\title{
Meridional Position Changes of the Sea Surface Temperature Anomalies in the North Pacific
}

\author{
TaO Wang, ${ }^{\mathrm{a}}$ Wenshou Tian, ${ }^{\mathrm{a}}$ TaO Lian, ${ }^{\mathrm{b}, \mathrm{c}, \mathrm{d}}$ Cheng Sun, ${ }^{\mathrm{e}}$ Fei Xie, ${ }^{\mathrm{e}}$ JiAnkai Zhang, ${ }^{\mathrm{a}}$ And QINGQING Yin ${ }^{\mathrm{a}}$ \\ ${ }^{a}$ Key Laboratory for Semi-Arid Climate Change of the Ministry of Education, College of Atmospheric Sciences, Lanzhou \\ University, China \\ ${ }^{\mathrm{b}}$ State Key Laboratory of Satellite Ocean Environment Dynamics, Second Institute of Oceanography, Ministry of Natural Resources, \\ Hangzhou, China \\ ' Southern Marine Science and Engineering Guangdong Laboratory (Zhuhai), Zhuhai, China \\ ${ }^{\mathrm{d}}$ School of Oceanography, Shanghai Jiao Tong University, Shanghai, China \\ ${ }^{\mathrm{e}}$ College of Global Change and Earth System Science, Beijing Normal University, Beijing, China
}

(Manuscript received 14 January 2021, in final form 31 August 2021)

\begin{abstract}
Changes in the meridional position of the sea surface temperature (SST) anomalies (SSTAs) associated with the interannual component (PC1-I) of the principal component 1 (PC1) of the first leading mode of the North Pacific SST (referred to here as PC1-I-related SSTAs) are investigated using reanalysis products and climate model output. It is found that the PC1-I-related SSTAs (or PC1-I anomalies) significantly shift southward at a rate of $1.04^{\circ}$ latitude per decade and have moved southward by $4.4^{\circ}$ since the $1960 \mathrm{~s}$. Our further analysis indicates that the southward shift of the PC1-I-related SSTAs is due to changes in ENSO teleconnections. Compared to the 1950-75 period (PRE era), the meridional width of the ENSO-induced tropical positive geopotential height (GH) anomaly is narrower during the 1991-2016 period (POST era), inducing a southward shift of the subtropical westerly anomaly over the North Pacific through geostrophic wind relations. This southward shift of the westerly anomaly favors the southward shift of the ENSO-induced negative GH anomaly (cyclonic circulation anomaly) over the North Pacific by positive vorticity forcing of the zonal wind shear. The southwardshifting GH anomaly associated with ENSO further forces the PC1-I anomaly to shift southward. Furthermore, the contraction of the ENSO-induced tropical positive GH anomaly is related to the contraction of the meridional width of ENSO. The modeling results support that the decrease in the ENSO meridional width favors the contraction of the ENSO-induced tropical positive GH anomaly and the southward shift of ENSO teleconnections over the North Pacific, contributing to the southward shift of the PC1-I anomaly.
\end{abstract}

KEYWORDS: Atmosphere-ocean interaction; ENSO; North Pacific Ocean; Sea surface temperature

\section{Introduction}

Studies of large-scale climate mode variations are important for improving climate predictability and understanding regional climate changes. The sea surface temperature (SST) variability in the North Pacific is one of the large-scale climate variability factors. The North Pacific SST variability, especially its first leading mode, has received much attention in the past decades (e.g., Mantua et al. 1997; Newman et al. 2003, 2016), including its phase change and its relationship with climate variability (e.g., Trenberth 1990; Miller et al. 1994; Tao et al. 2020).

Previous studies found that the first leading mode of the North Pacific SST has experienced dramatic phase changes in the past century (e.g., Mantua et al. 1997; Mantua and Hare 2002), of which the $1976 / 77$ transition is the best known and most extensively studied (e.g., Trenberth 1990; Graham 1994; Trenberth and Hurrell 1994; Miller et al. 1994; Schneider and Cornuelle 2005). Changes in the phase of the first leading mode of the North Pacific SST are closely correlated with anomalies of the Pacific ecosystem and fish stocks (Mantua et al. 1997; Miller and Schneider 2000); North American precipitation, streamflow, and surface temperature anomalies

Corresponding author: Wenshou Tian, wstian@lzu.edu.cn
(Cayan et al. 1998; Dettinger et al. 1998; Barlow et al. 2001; Mantua and Hare 2002); surface temperature anomalies in northeastern Asia (Minobe 2000); variations in the Asian monsoon (Krishnan and Sugi 2003; Wang et al. 2015); and anomalies in the Arctic stratospheric polar vortex (Jadin et al. 2010; Hurwitz et al. 2012; Woo et al. 2015; Hu and Guan 2018). In addition, changes in the variances of the North Pacific SST variability have also been reported; for example, Liguori and Di Lorenzo (2018) found that the Pacific decadal variability has increased in recent decades and is expected to increase with climate warming.

As mentioned above, many studies reported changes in the phase of the first leading mode of the North Pacific SST, as well as its relationship with climate variability. However, changes in the position of the first leading mode received little attention in past studies. Thus, a question arises as to whether the position of the first leading mode of the North Pacific SST also experienced changes in past decades. Some studies found that ENSO-induced teleconnections over the North Pacific shifted toward lower latitudes in recent decades (e.g., Wang et al. 2007; He et al. 2013; Pak et al. 2014; Zhang et al. 2017). Moreover, it is well known that ENSO forces the North Pacific SST anomalies (SSTAs) via influencing the Aleutian low (i.e., the "atmospheric bridge"), which affects surface heat fluxes, winddriven mixing, and Ekman transport in the upper ocean and thereby the SSTAs in the North Pacific (e.g., Alexander et al. 
(a) SSTAs regressed onto PC1

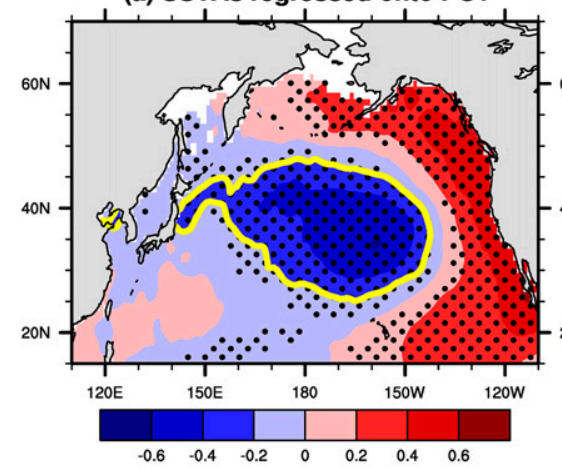

(d) PC1 index

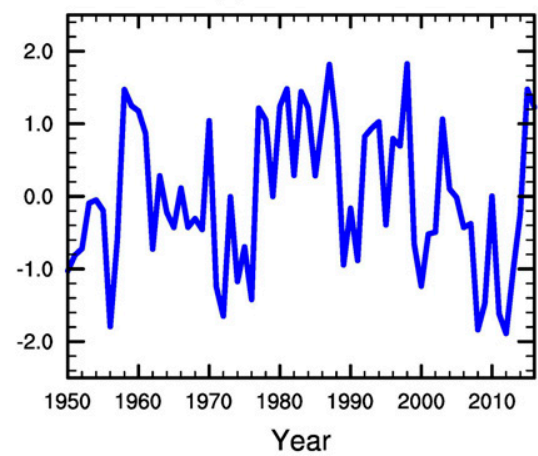

(b) SSTAs regressed onto PC1-I

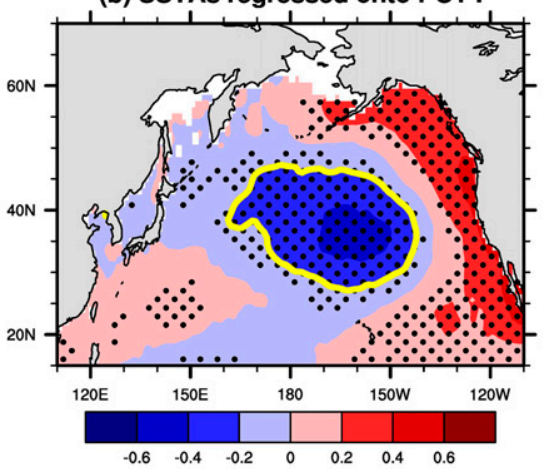

(e) PC1-I index

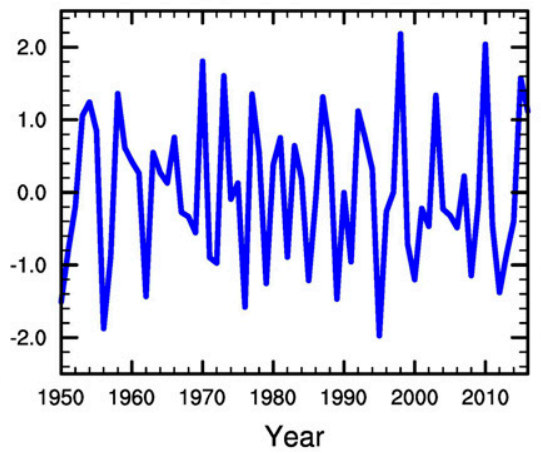

(c) SSTAs regressed onto PC1-D

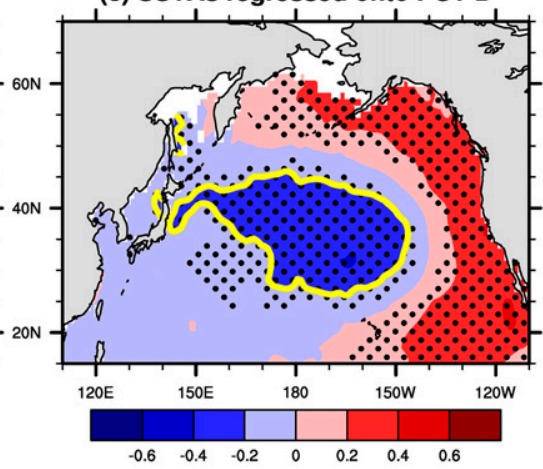

(f) PC1-D index

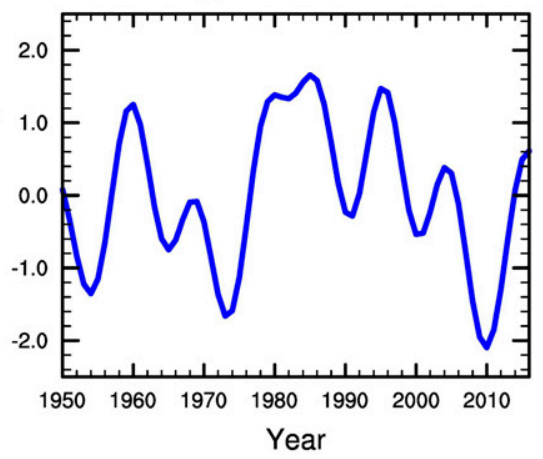

FIG. 1. (a) Wintertime (NDJFMA) sea surface temperature anomalies (SSTAs; K) regressed onto the principal component 1 (PC1) of the first EOF mode of the SST field in the North Pacific $\left(20.5^{\circ}-65.5^{\circ} \mathrm{N}, 124.5^{\circ} \mathrm{E}-100.5^{\circ} \mathrm{W}\right)$. The interannual component of the PC1 is referred as PC1-I index, which is obtained using an 8-yr high-pass filter of the PC1. The decadal-to-multidecadal component of the PC1 is referred as PC1-D, which is obtained using an 8-yr low-pass filter of the PC1. (b) SSTAs regressed onto the PC1-I index. (c) SSTAs regressed onto the PC1-D index. The yellow contours in (a)-(c) denote the $-0.2-\mathrm{K}$ contour, which is regarded as the border of the negative center of the SSTA field. The dotted regions are statistically significant at the 95\% confidence level according to Student's $t$ test. (d)-(f) The standardized and detrended time series of PC1, PC1-I, and PC1-D indexes, respectively.

2002; Newman et al. 2003, 2016; Schneider and Cornuelle 2005; Alexander and Scott 2008; Fang and Yang 2016). Therefore, it is possible that the position of the interannual component of the first leading mode of the North Pacific SST may change due to the shift of the ENSO teleconnections.

The interannual component of the first principal component (PC1) of the first leading mode of the North Pacific SST is referred as PC1-I in this paper. The aim of this paper is to explore changes in the meridional position of the PC1-I-related SSTAs and corresponding physical mechanisms. The remainder of this paper is organized as follows. Section 2 shows the data and methods. Section 3 describes the southward shift of the SSTAs associated with the PC1-I since the 1960s. Section 4 analyzes the possible mechanisms responsible for the southward shift of the PC1-I-related SSTAs. Section 5 gives the conclusions and discussion.

\section{Data and methods}

\section{a. Observations and reanalysis datasets}

In this study, winter refers to the months from November of a given year to April of the following year (NDJFMA); for example, the winter of 1950 refers to the period from November 1949 to April 1950. Monthly geopotential height and zonal and meridional wind data with a horizontal resolution of $2.5^{\circ} \times 2.5^{\circ}$ (latitude $\times$ longitude) are obtained from the National Centers for Environmental Prediction (NCEP) and the National Center for Atmospheric Research (NCAR) reanalysis products (Kalnay et al. 1996). SST data are obtained from the Hadley Centre Sea Ice and Sea Surface Temperature Dataset version 1 (HadISST; Rayner et al. 2003) product with a horizontal resolution of $1^{\circ} \times 1^{\circ}$ (latitude $\times$ longitude) and from the Extended Reconstructed Sea Surface Temperature (ERSSTv4; Huang et al. 2015) dataset with a horizontal resolution of $2^{\circ} \times 2^{\circ}$ (latitude $\times$ longitude). The data used in this study represent monthly means for the period from November 1949 to April 2016; for this period, various atmospheric data are available, thereby allowing the mechanisms to be analyzed.

\section{b. Methods}

The principal component 1 ( $\mathrm{PC} 1$ ) of the first empirical orthogonal function (EOF) mode of the wintertime (NDJFMA) SST field in the North Pacific $\left(20.5^{\circ}-65.5^{\circ} \mathrm{N}, 124.5^{\circ} \mathrm{E}-100.5^{\circ} \mathrm{W}\right)$ is shown in Fig. 1d. The explained variance of the first EOF 
mode is $32.3 \%$, and the spatial patterns of the SSTAs regressed by $\mathrm{PC} 1$ are shown in Fig. 1a. Note that the time series of PC1 contains mixed time scales, including interannual, decadal, and multidecadal time scales (e.g., Biondi et al. 2001; Newman et al. 2016). Based on Fourier decomposition, we obtain the interannual component (referred hereafter as PC1-I) of the PC1 using an 8-yr high-pass filter, as shown in Fig. 1e. The SSTAs regressed onto the PC1-I are shown in Fig. 1b. The decadal-tomultidecadal components (referred hereafter as PC1-D) of the PC1 are obtained using an 8-yr low-pass filter (Fig. 1f), and the corresponding regression patterns of SSTAs are shown in Fig. 1c. Due to the limited length (1950-2016) of various reanalysis products, this study focuses on changes in the meridional position of the SSTAs associated with the interannual component of the first leading mode of the North Pacific SST (i.e., PC1-I-related SSTAs). Note that the results are not sensitive to small changes in the truncation period, such as the use of a 7- or 9-yr high-pass filter (not shown). In addition, the Niño-3.4 index is defined as the area-averaged SSTAs in the Niño-3.4 region $\left(5^{\circ} \mathrm{S}-5^{\circ} \mathrm{N}, 170^{\circ}-120^{\circ} \mathrm{W}\right)$.

In this study, we focus on the meridional position of the PC1-I-related SSTAs. It should be noted that, for brevity, the positive phases of various regressed fields are used to describe the corresponding anomalies hereafter. The negative center of the PC1-I-related SSTAs (Fig. 1b) has a well-defined elliptical shape in the central North Pacific. Thus, we use the position of this negative center to represent the position of the PC1-I-related SSTAs. The border of this negative center is defined as the $-0.2-\mathrm{K}$ contour (yellow contour) in this study because the SSTAs less than $-0.2 \mathrm{~K}$ are statistically significant (Fig. 1b). Three approaches are used to calculate the central latitude of this negative center. The first approach (approach 1) considers that the central latitude of this negative center refers to the averaged latitude of the negative SSTAs enclosed by its border (yellow contour; Fig. 1b), comprising the weights of the SSTAs and the latitude factor, as shown in Eq. (1):

$$
\text { Latc }=\frac{\sum_{i=1}^{n} \operatorname{Lat}(i) \times \operatorname{SST}(i) \times \cos [\operatorname{Lat}(i)]}{\sum_{i=1}^{n} \operatorname{SST}(i) \times \cos [\operatorname{Lat}(i)]},
$$

where $n$ is the total number of grids with SSTAs less than $-0.2 \mathrm{~K}$ (i.e., within the border) in the central North Pacific $\left(20^{\circ}-50^{\circ} \mathrm{N}\right.$, $\left.150^{\circ} \mathrm{E}-140^{\circ} \mathrm{W}\right)$. The reason we choose the region within $20^{\circ}-$ $50^{\circ} \mathrm{N}, 150^{\circ} \mathrm{E}-140^{\circ} \mathrm{W}$ for this calculation is that variation in the position of this negative center (Fig. 1b) does not exceed this region in the studied period. Lat $(i)$ and $\operatorname{SST}(i)$ are the latitude and SST anomaly (SSTA) of the $i$ th grid cell, respectively. Latc is the central latitude of this negative pole. The second approach (approach 2) is similar to approach 1 but does not consider the weights of the SSTAs, as shown in Eq. (2):

$$
\text { Latc }=\frac{\sum_{i=1}^{n} \operatorname{Lat}(i) \times \cos [\operatorname{Lat}(i)]}{\sum_{i=1}^{n} \cos [\operatorname{Lat}(i)]} \text {. }
$$

The third approach (approach 3 ) is that the central latitude of the negative center refers to the latitude of the grid cell in which the minimum SSTA is recorded. Therefore, the central latitude of this negative center is derived based on the three approaches described above, and this central latitude is regarded as the central latitude of the PC1-I-related SSTAs in this study to quantify the long-term changes in the meridional position of the PC1-I-related SSTAs.

Next, the PC1-I index (Fig. 1e) and 21-yr-run regression are used to obtain the spatial pattern of the PC1-I-related SSTAs in each year. For example, the PC1-I-related SSTAs in 1960 (1961) represent the SSTAs regressed onto the PC1-I index during 1950-70 (1951-71). Then, using the abovedescribed three approaches, the central latitude of the PC1I-related SSTAs in each year is obtained. Note that, here, we choose the $-0.2-\mathrm{K}$ contour as the border of the PC1-I-related SSTAs and use a 21-yr-run regression. However, if we change the criterion, for example, by using the $-0.1-\mathrm{K}$ contour or a 51-yr-run regression, the results are similar, suggesting that the results are not sensitive to the methods.

\section{c. Data from coupled numerical experiments of CMIP5}

To investigate the effects of the meridional width of ENSO on the North Pacific SST, the results obtained from phase 5 of the Coupled Model Intercomparison Project (CMIP5) are analyzed in this study. The model output of the last 100 years (1905/06-2004/05) obtained from CMIP5 historical runs are analyzed, and this long-term (100-yr) simulation alleviates the effects of the internal variabilities in the atmosphere and ocean on the results. In HadISST, the correlation coefficient between the wintertime Niño-3.4 index and the principal component 1 of the first EOF mode of the North Pacific SST is 0.66 (at the $95 \%$ confidence level) in HadISST, and it is 0.64 (at the 95\% confidence level) in ERSST, consistent with previous studies (e.g., Schneider and Cornuelle 2005; Newman et al. 2016). A total of 26 out of 36 models from CMIP5 capture the significant $(p<0.05)$ relationship between the Niño-3.4 and the principal component 1 of the first EOF mode of the North Pacific SST, namely CanESM2, CMCC-CESM, CMCC-CM, CMCC-CMS, CSIRO-Mk3.6.0, FGOALS-g2, GFDL-CM2p1, GFDL CM3, GFDL-ESM2G, HadCM3, HadGEM2-AO, HadGEM2-CC, HadGEM2-ES, INM-CM4, IPSL-CM5A-LR, IPSL-CM5B-LR, MIROC5, MIROC-ESM, MIROC-ESM-CHEM, MPI-ESMLR, MPI-ESM-MR, MPI-ESM-P, MRI-CGCM3, MRI-ESM1, NorESM1-M, and NorESM1-ME. These results suggest that the 26 models have outstanding abilities to simulate the close observed relationship between ENSO variability and the North Pacific SST variability, and thus the results obtained from these 26 models are analyzed in this study.

\section{Changes in the meridional position of the PC1-I-related SSTAs since the 1960s}

Figure 2 shows the regression patterns of the PC1-I-related SSTAs during 1950-70 (Fig. 2a), 1970-90 (Fig. 2b), and 19902010 (Fig. 2c). The general characteristics of the PC1-I-related SSTAs are similar among the three periods, and the PC1-Irelated SSTAs display a dipolar structure in the east-west 
(a) Pattern of PC1-I_SSTAs (1950-1970)

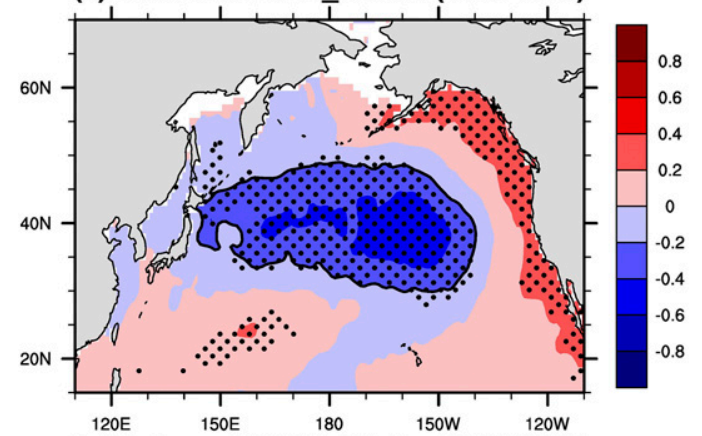

(c) Pattern of PC1-ISSTAs (1990-2010)

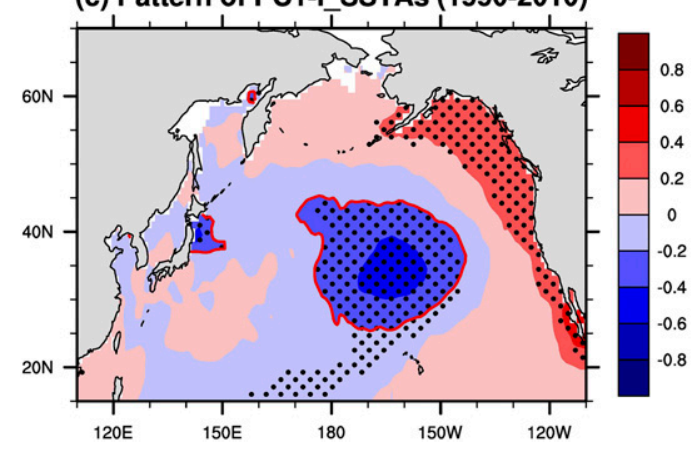

(b) Pattern of PC1-I_SSTAs (1970-1990)

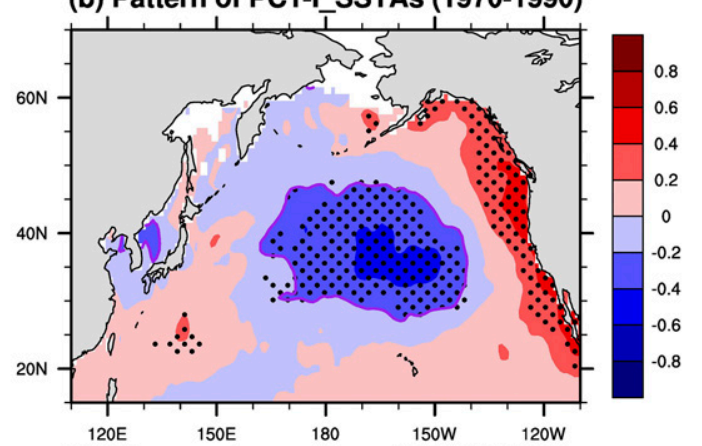

(d) Changes in position of PC1-I_SSTAs

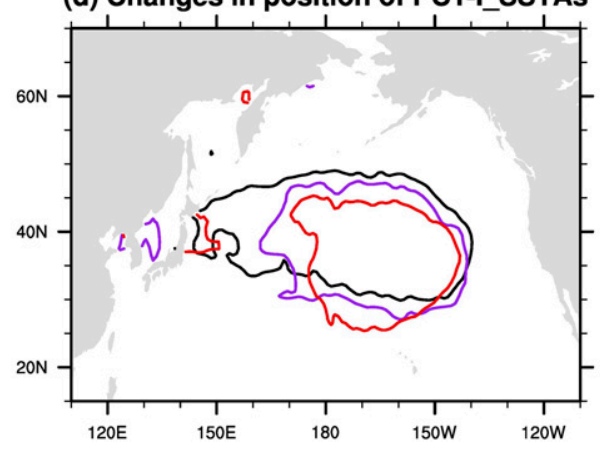

FIG. 2. SSTAs (K) regressed onto the PC1-I index during (a) 1950-70, (b) 1970-90, and (c) 1990-2010 from HadISST. The black, purple, and red contours in (a)-(c) denote the $-0.2-\mathrm{K}$ contour of the SSTA fields, which is regarded as the border of the PC1-I-related SSTAs. (d) The black, purple, and red contours in (a)-(c) are also superimposed to facilitate direct comparison. The dotted regions are statistically significant at the $95 \%$ confidence level according to Student's $t$ test.

direction in the middle latitudes $\left(30^{\circ}-50^{\circ} \mathrm{N}\right.$; Fig. 2$)$ in all of the three periods. Therefore, the main structures of the PC1-Irelated SSTAs did not change among these periods, but the positions of the PC1-I-related SSTAs changed. Figure 2d indicates that the PC1-I-related SSTAs shift southward during 1970-90 (purple contour) compared to that during 1950-70 (black contour), and the PC1-I-related SSTAs shift farther southward during 1990-2010 (red contour) compared to that during 1970-90 (purple contour). Based on approach 1 and HadISST, the central latitudes of the PC1-I-related SSTAs during 1950-70, 1970-90, and 1990-2010 are 39.5, $37.3^{\circ}$, and $35.2^{\circ} \mathrm{N}$, respectively, indicating a southward shift of the PC1I-related SSTAs.

Two 26-yr-long periods (1950-75 and 1991-2016) are chosen to perform a comparative analysis to further understand the southward shift of the PC1-I-related SSTAs, and the results are not sensitive to small changes in the periods, for example, the use of 1950-80 and 1986-2016. For the sake of brevity, the two periods are denoted as the PRE (1950-75) and POST (19912016) eras hereafter. The regressed and composited SSTAs associated with the PC1-I are shown in Figs. 3 and 4. The regressed SSTAs indicate that the PC1-I-related SSTAs shift southward during the POST era (green contour) compared to that during the PRE era (purple contour) (Figs. 3c and 4c). The composite results are similar to the regressed results, and the PC1-I events are shown in Table 1. The composite results also indicate that the PC1-I-related SSTAs shift southward during the POST era (green contour) compared to that during the PRE era (purple contour) (Figs. $3 f$ and 4 f).

To obtain the details of the changes in the central latitude of the PC1-I-related SSTAs, Figs. 5a-f display the time series of the central latitude of PC1-I-related SSTAs based on different approaches (approaches 1-3), different borders $(-0.2,-0.1$, and $0 \mathrm{~K})$, and different datasets (ERSST and HadISST). Interestingly, the central latitude of the PC1-Irelated SSTAs shows a significant southward shift since the 1960s, and this shift is not sensitive to the various approaches and data used. The linear trend of each time series in Figs. 5a-f is listed in Table 2. Although the magnitudes of the linear trends range from $-1.62^{\circ}$ to $-0.75^{\circ}$ decade $^{-1}$ among the different approaches and data used (Table 2), all results show a significant (at the $99 \%$ confidence level) negative trend. Based on approach 1 and a $-0.2-\mathrm{K}$ border, the linear trend of the central latitude of the PC1-I-related SSTAs is $-1.04^{\circ}$ latitude decade $^{-1}$ in HadISST, suggesting that the PC1-I-related SSTAs shift southward at a rate of $\sim 116 \mathrm{~km}^{\text {decade }}{ }^{-1}$ since 1960 . Specifically, the central latitudes of the PC1-I-related SSTAs in the $1960 \mathrm{~s}, 1970 \mathrm{~s}, 1980 \mathrm{~s}, 1990 \mathrm{~s}$, and $2000 \mathrm{~s}$ are $39.2^{\circ}, 37.7^{\circ}$, $37.4^{\circ}, 36.2^{\circ}$ and $34.8^{\circ} \mathrm{N}$, respectively, indicating that the PC1-I-related SSTAs have moved southward by $4.4^{\circ}$ of latitude since the 1960s. Note that the results shown in Figs. 5a-f are based on a 21-yr-run regression. To test whether the results are sensitive to the methods, Figs. $5 \mathrm{~g}$ and $5 \mathrm{~h}$ further show the central latitude of the PC1-I-related SSTAs based 
(a) 1950-1975:SSTAs regressed onto PC1-I

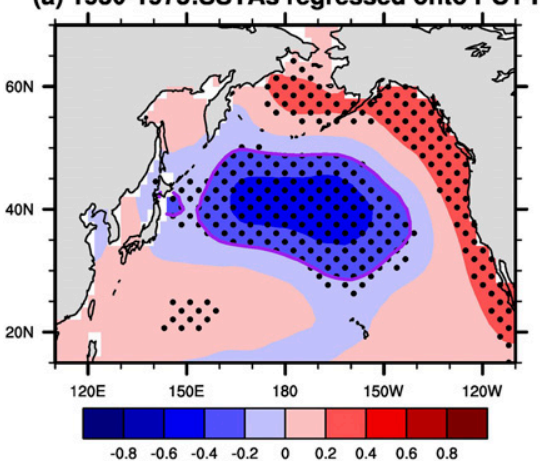

(d) 1950-1975: + PC1-I minus - PC1-I

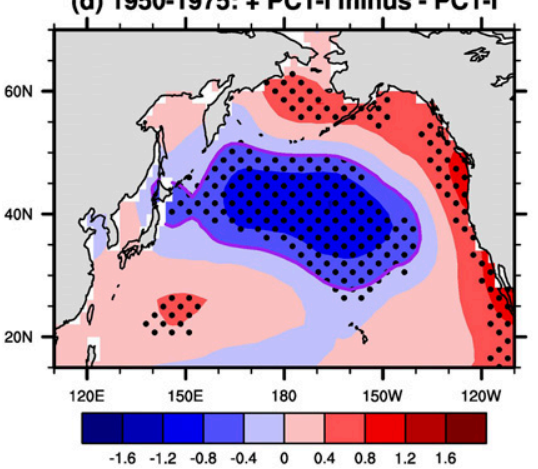

(b) 1991-2016:SSTAs regressed onto PC1-I

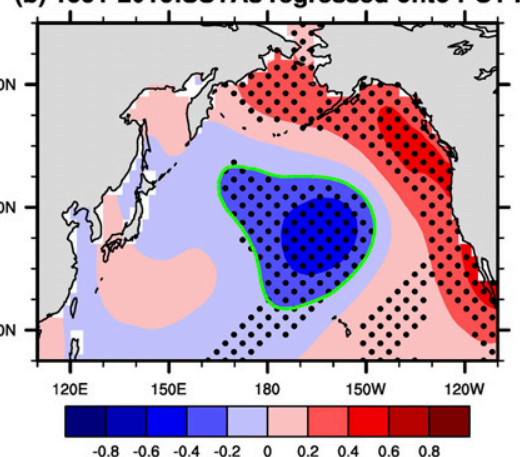

(e) 1991-2016: + PC1-I minus - PC1-I

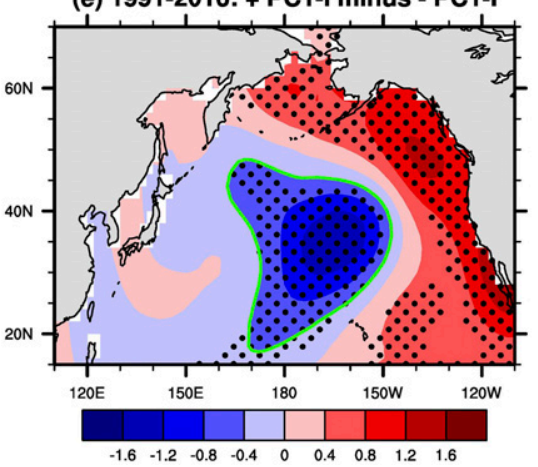

(c) Position of PC1-ISSSTAs (regressed)

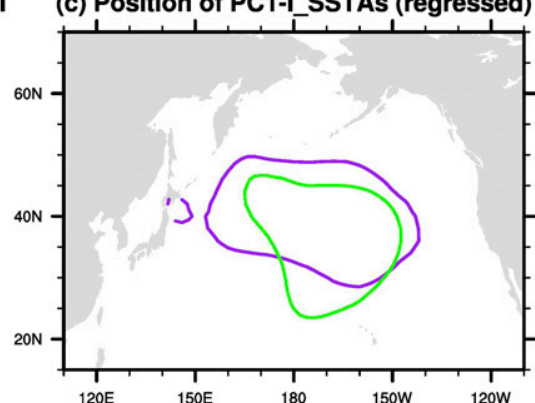

(f) Position of PC1-I_SSTAs (composited)

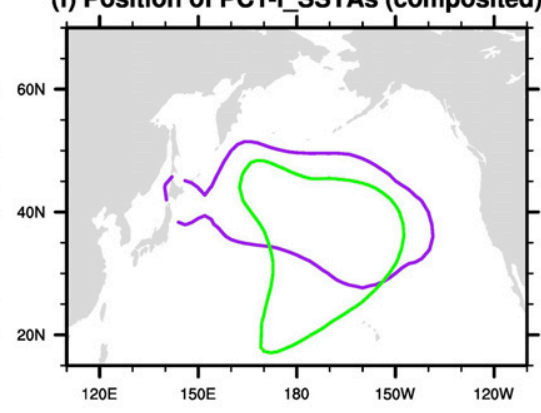

FIG. 3. (a),(b) SSTAs (K) regressed onto the PC1-I index during 1950-75 and 1991-2016, respectively, based on ERSST. The purple and green contours denote the $-0.2-\mathrm{K}$ contour of the SSTA fields in (a) and (b), respectively, and (c) these are superimposed to facilitate direct comparison. (d),(e) Composite SSTAs associated with PC1-I events during 1950-75 and 1991-2016, respectively. The purple and green contours denote the $-0.4-\mathrm{K}$ contour of the SSTA fields in (d) and (e), respectively, and (f) these are superimposed to facilitate direct comparison. The PC1-I events are shown in Table 1 . The dotted regions are statistically significant at the $95 \%$ confidence level according to Student's $t$ test.

on 21-, 31-, 41-, and 51-yr-run regressions. It is apparent that the central latitude of the PC1-I-related SSTAs shows a significant southward shift since the 1960s, and the results are not sensitive to the methods (Figs. $5 \mathrm{~g}, \mathrm{~h}$ ).

Note that in this study, we conduct the EOF analyses on the North Pacific SST and derive the PC1 of the first leading mode. Then the meridional position of the SSTAs associated with the interannual component (PC1-I) of the PC1 is investigated and the results are shown in Figs. 2-5. However, when we conduct EOF analyses on the interannual component of the North Pacific SST and then get the corresponding PC1 [referred to here as PC1 (SSTI)], the results associated with the PC1 (SSTI) are similar to those associated with the PC1-I (not shown), suggesting that the results are not sensitive to the small changes in method.

\section{Possible mechanisms responsible for the southward shift of the PC1-I-related SSTAs}

In this section, possible mechanisms responsible for the southward shift of the PC1-I-related SSTAs (or PC1-I anomaly) are analyzed. Figure 6 displays the geopotential height (GH) and horizontal wind anomalies regressed onto the PC1-I index in the PRE (1950-75) and POST (1991-2016) eras.
During the PRE era, the PC1-I-related negative GH anomaly (cyclonic circulation anomaly) is located over the northern North Pacific $\left(35^{\circ}-65^{\circ} \mathrm{N}, 150^{\circ} \mathrm{E}-140^{\circ} \mathrm{W}\right)$ (Fig. 6a), which forces the North Pacific SSTAs (i.e., PC1-I anomaly) (Figs. 3a and 4a) through surface heat fluxes, wind-driven mixing, and Ekman transport in the upper ocean (e.g., Alexander et al. 2002; Newman et al. 2003, 2016; Schneider and Cornuelle 2005; Alexander and Scott 2008; Fang and Yang 2016). However, this negative $\mathrm{GH}$ anomaly and corresponding cyclonic circulation anomaly shift to the central regions of the North Pacific $\left(25^{\circ}-55^{\circ} \mathrm{N}, 160^{\circ} \mathrm{E}-130^{\circ} \mathrm{W}\right)$ during the POST era (Fig. $\left.6 \mathrm{c}\right)$, forcing the PC1-I anomaly to also relocate in the central regions (Figs. 3b and 4b). The PC1-I-related GH anomaly in the lower troposphere also shifts toward lower latitudes during the POST era (Fig. 6d) compared to that during the PRE era (Fig. 6b). Thus, Fig. 6 indicates that the southward shift of the PC1-I-related SSTAs (Figs. 2-5) is related to the southward shift of the PC1-I-related negative GH anomaly (cyclonic circulation anomaly) over the North Pacific, which forces the PC1-I anomaly (e.g., Fang and Yang 2016; Newman et al. 2016). However, determining which factor leads to the southward shift of the PC1-I-related negative GH anomaly over the North Pacific, and thereby the southward shift of the PC1-I anomaly, represents a key question. 
(a) 1950-1975:SSTAs regressed onto PC1-I

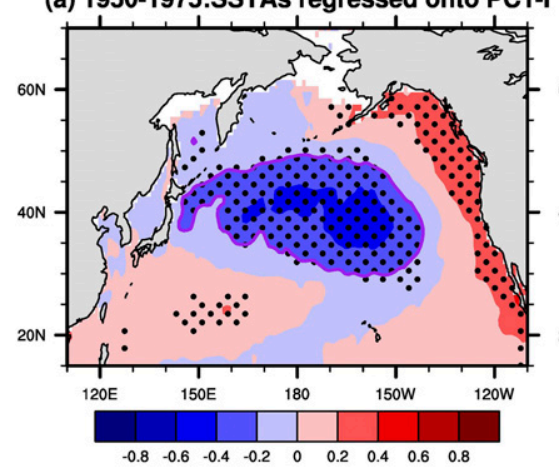

(d) 1950-1975: + PC1-I minus - PC1-I

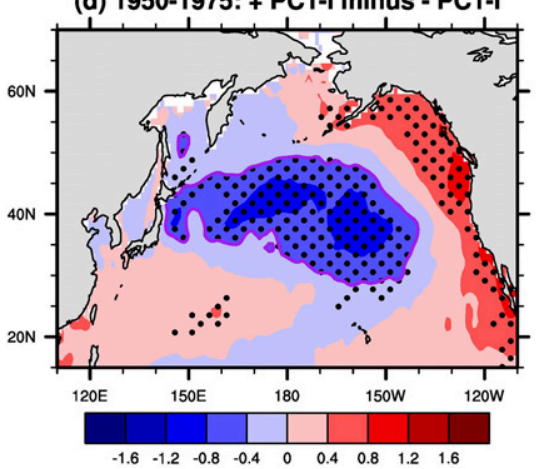

(b) 1991-2016:SSTAs regressed onto PC1-I
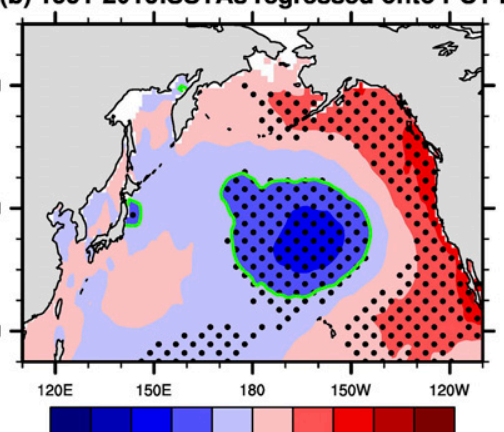

$\begin{array}{llllllllll}-0.8 & -0.6 & -0.4 & -0.2 & 0 & 0.2 & 0.4 & 0.6 & 0.8\end{array}$

(e) 1991-2016: + PC1-I minus - PC1-I

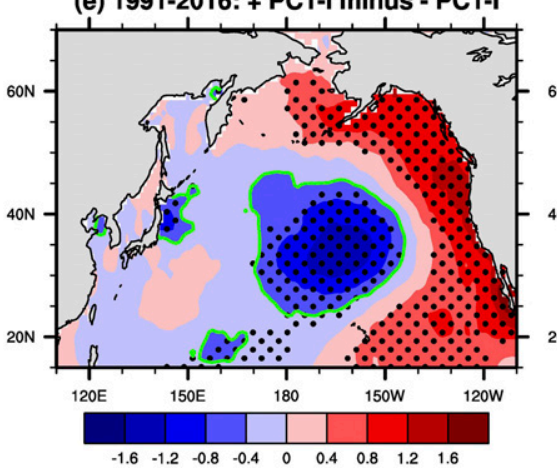

(c) Position of PC1-I SSTAs (regressed)

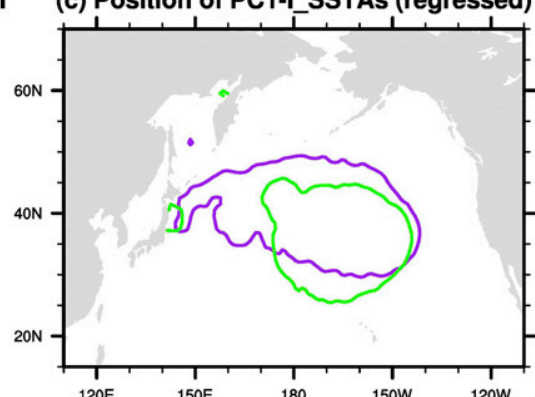

(f) Position of PC1-I_SSTAs (composited)

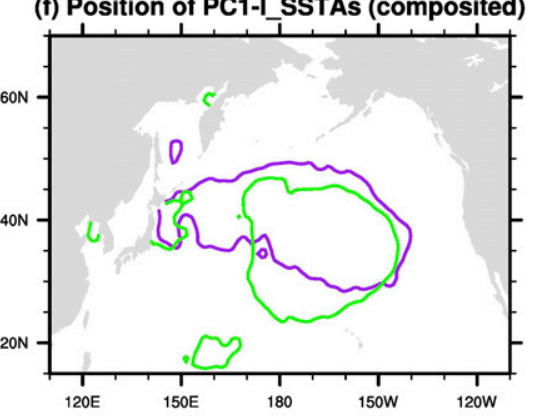

FIG. 4. As in Fig. 3, but derived from the HadISST dataset.

Note that the spatial pattern of the PC1-I-related SSTAs (Figs. 2-4) looks like the Pacific decadal oscillation (PDO; e.g., Mantua and Hare 2002; Wu et al. 2011). Regarding the PDO dynamics, the processes that contribute to the decadal-tomultidecadal variability in the PDO are complex, including midlatitude air-sea interactions (e.g., Latif and Barnett 1994, 1996; Kwon and Deser 2007; Frankignoul et al. 2011; Taguchi et al. 2012; Fang and Yang 2016), ocean gyre dynamics involving Rossby waves (e.g., Frankignoul et al. 1997; Qiu and Chen 2005; Taguchi et al. 2007; Sasaki and Schneider 2011; Sasaki et al. 2013; Miyasaka et al. 2014), and reemergence mechanisms (e.g., Namias and Born 1970, 1974; Alexander and Deser 1995; Alexander et al. 1999, 2001, 2002). However, on the interannual time scale, it is well known that ENSO is an important factor that forces the PDO-like SSTAs (i.e., PC1-I anomaly) via the "atmospheric bridge" (e.g., Newman et al. 2003, 2016; Schneider and Cornuelle 2005). Moreover, some studies have found that the ENSO-induced GH anomaly over the North Pacific has shifted southward in recent decades (e.g., Wang et al. 2007; He et al. 2013; Pak et al. 2014; Zhang et al. 2017); this result is similar to the southward shift of the PC1-I- related GH anomaly shown in this study (Fig. 6). Therefore, it is likely that the southward shift of the PC1-I-related negative GH anomaly over the North Pacific may have resulted from ENSO changes. Figures $7 \mathrm{a}, 7 \mathrm{~b}, 7 \mathrm{~d}$, and $7 \mathrm{e}$ show changes in the ENSO-induced GH anomaly over the North Pacific. It should be noted that during the PRE era, the ENSO-induced negative $\mathrm{GH}$ anomaly (cyclonic circulation anomaly) is located over the northern North Pacific (Figs. 7a,b), forcing the PC1-I-like SSTAs also located in the northern regions (red contour; Fig. 7c) through surface heat fluxes, wind-driven mixing, and Ekman transport in the upper ocean (e.g., Alexander et al. 2002; Newman et al. 2003, 2016; Schneider and Cornuelle 2005; Alexander and Scott 2008; Fang and Yang 2016). However, this negative $\mathrm{GH}$ anomaly associated with ENSO shifts toward lower latitudes during the POST era (Figs. 7d,e), leading to the southward shift of the PC1-I-like SSTAs (green contour; Fig. 7f). Therefore, Fig. 7 indicates that the southward shift of the ENSO-induced negative GH anomaly (cyclonic circulation anomaly) over the North Pacific contributes to the southward shift of the PC1-I anomaly. Note that these results are based on the original Niño-3.4 index with the linear trends removed.

TABLE 1. Positive and negative PC1-I events during 1950-75 and 1991-2016 based on the 0.5 standard deviation of the PC1-I index.

\begin{tabular}{ccc}
\hline \hline & $1950-75$ & $1991-2016$ \\
\hline + PC1-I & $1953,1954,1955,1958,1959,1963,1966$, & $1992,1993,1998,2003,2010,2015,2016$ \\
-PC1-I & 1970,1973 & $1991,1995,1999,2000,2008,2012,2013$ \\
\hline
\end{tabular}


(a) Central latitude (HadISST, Approach1)

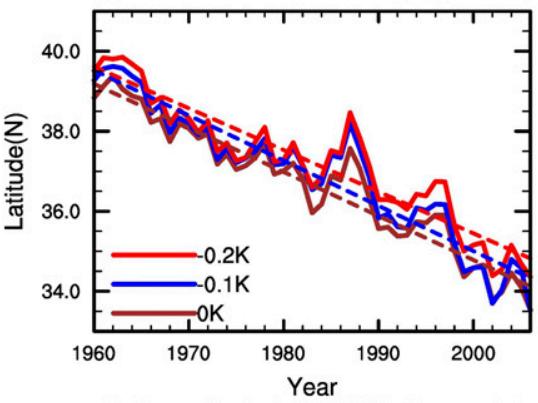

(d) Central latitude (ERSST, Approach1)

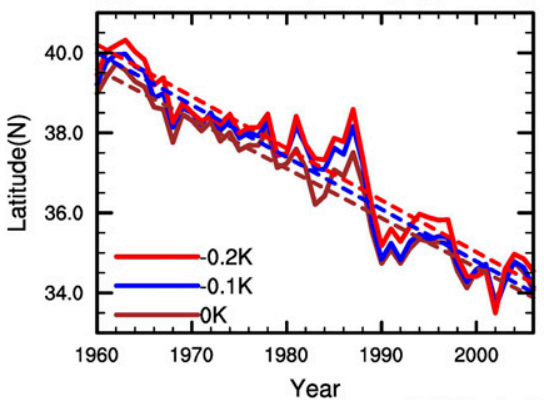

(g) Central latitude (HadISST)

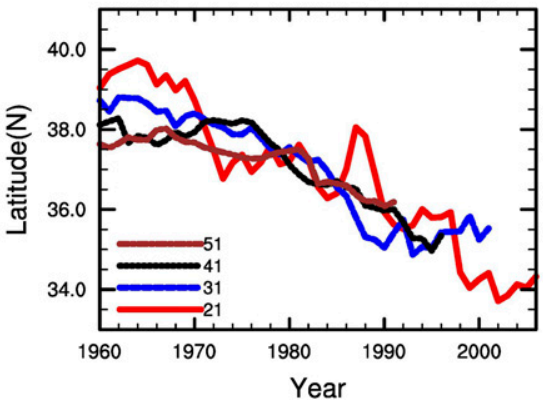

(b) Central latitude (HadISST, Approach2)

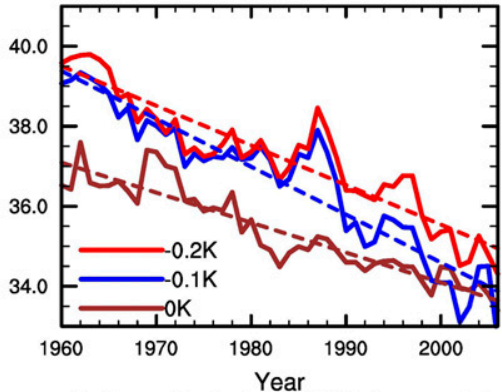

(e) Central latitude (ERSST, Approach2)

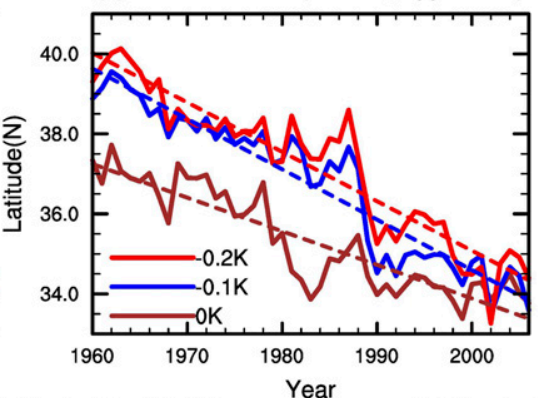

(c) Central latitude (HadISST, Approach3)

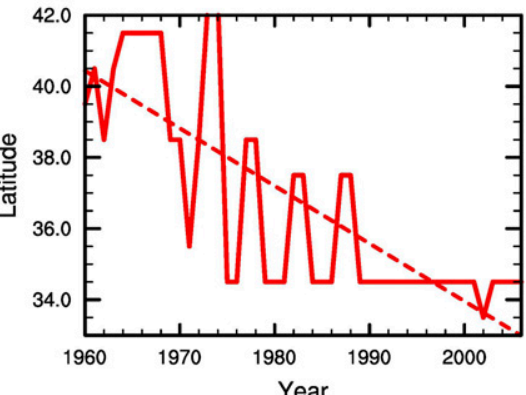

(f) Central latitude (ERSST, Approach3)

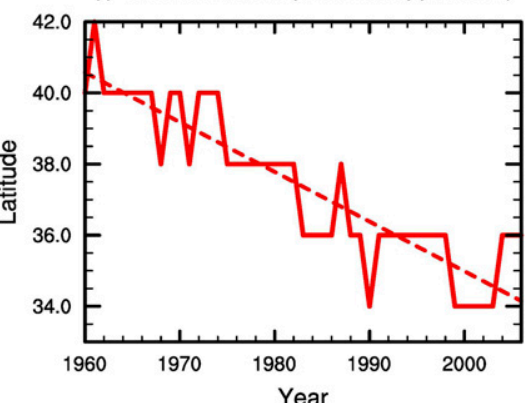

(h) Central latitude (ERSST)

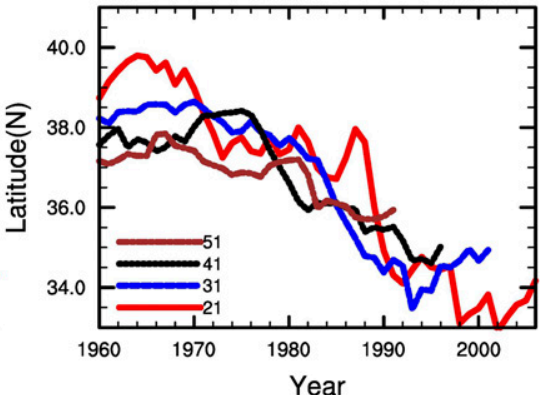

FIG. 5. (a)-(c) Solid lines are the time series of the central latitude of the PC1-I-related SSTAs based on approach 1, approach 2, and approach 3 from HadISST, respectively. The dashed lines are the corresponding linear fit lines. The red, blue, and brown lines in (a) and (b) indicate that the border of the PC1-I-related SSTAs is defined as the $-0.2-,-0.1$ - and 0-K contours, respectively. (d)-(f) As in (a)-(c), but the SST data are from the ERSST dataset. The linear trend of each line is shown in Table 2. (g) The time series of the central latitude of the PC1-I-related SSTAs based on 21- (red), 31- (blue), 41- (black), and 51-yr-run (brown) regressions from the HadISST dataset. (h) As in (g), but derived from the ERSST dataset.

However, the results obtained using the Niño-3.4 index with a 2-8-yr bandpass filter are rather similar to those obtained based on the original Niño-3.4 index (not shown), suggesting that ENSO is dominated by interannual variability.

To understand the physical mechanisms responsible for the southward shift of the ENSO-induced circulation anomaly over the North Pacific, Figs. 8 a and 8 b show the tropical GH anomalies associated with ENSO. It is apparent that the tropical positive GH anomaly associated with ENSO is wider and extends farther north in the Northern Hemisphere (NH) during the PRE era (Fig. 8a) compared to that during the POST era (Fig. 8b). According to geostrophic wind relations, this tropical positive $\mathrm{GH}$ anomaly favors a westerly anomaly over the subtropics of the $\mathrm{NH}\left(20^{\circ}-40^{\circ} \mathrm{N}, 180^{\circ} \mathrm{E}-180^{\circ} \mathrm{W}\right.$;

TABLE 2. The linear trend $\left({ }^{\circ}\right.$ latitude per decade) of the central latitude of the PC1-I-related SSTAs during 1960-2006 based on different approaches and datasets. Asterisks indicate that the linear trend is statistically significant at the $99 \%$ confidence level.

\begin{tabular}{|c|c|c|c|c|c|c|c|}
\hline \multicolumn{4}{|c|}{ HadISST } & \multicolumn{4}{|c|}{ ERSST } \\
\hline Border (K) & Approach 1 & Approach 2 & Approach 3 & Border $(\mathrm{K})$ & Approach 1 & Approach 2 & Approach 3 \\
\hline-0.2 & $-1.04 *$ & $-0.99 *$ & $-1.62 *$ & -0.2 & $-1.30 *$ & $-1.23^{*}$ & $-1.40 *$ \\
\hline-0.1 & $-1.13^{*}$ & $-1.20 *$ & & -0.1 & $-1.30 *$ & $-1.26^{*}$ & \\
\hline 0 & $-1.10^{*}$ & $-0.75^{*}$ & & 0 & $-1.24^{*}$ & $-0.84 *$ & \\
\hline
\end{tabular}


(a)1950-1975:H500 regressed onto PC1-I

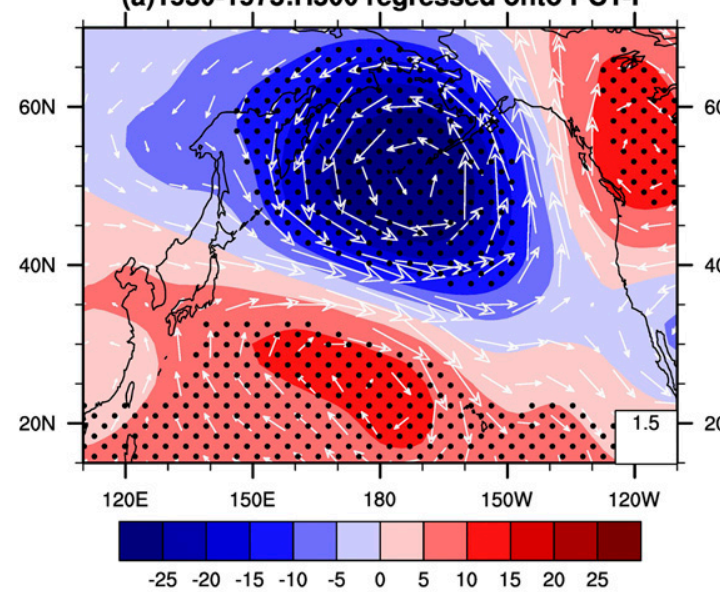

(c)1991-2016:H500 regressed onto PC1-I

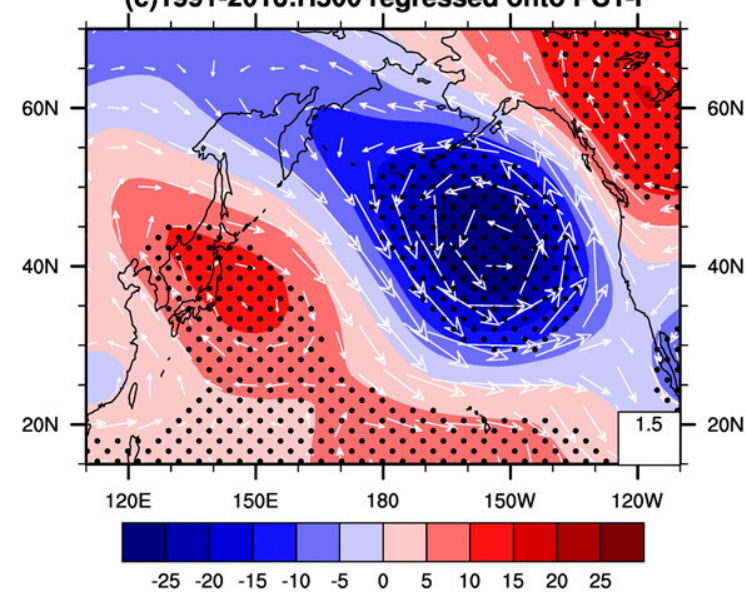

(b)1950-1975:H1000 regressed onto PC1-I

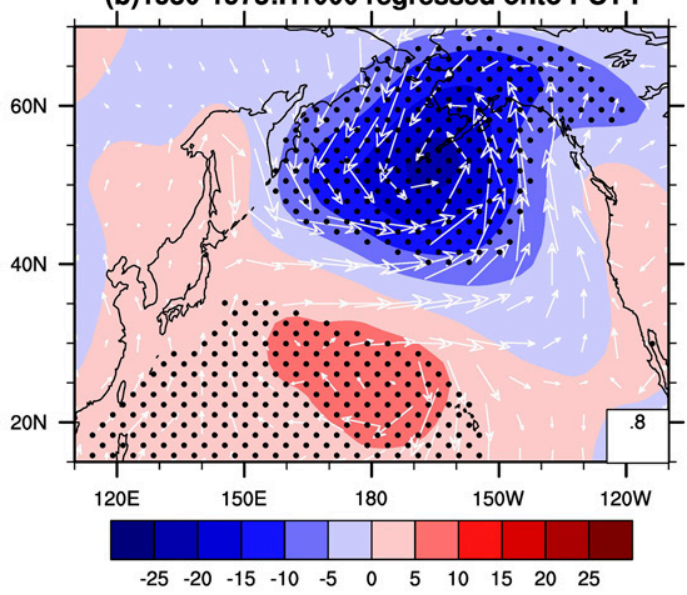

(d)1991-2016:H1000 regressed onto PC1-I

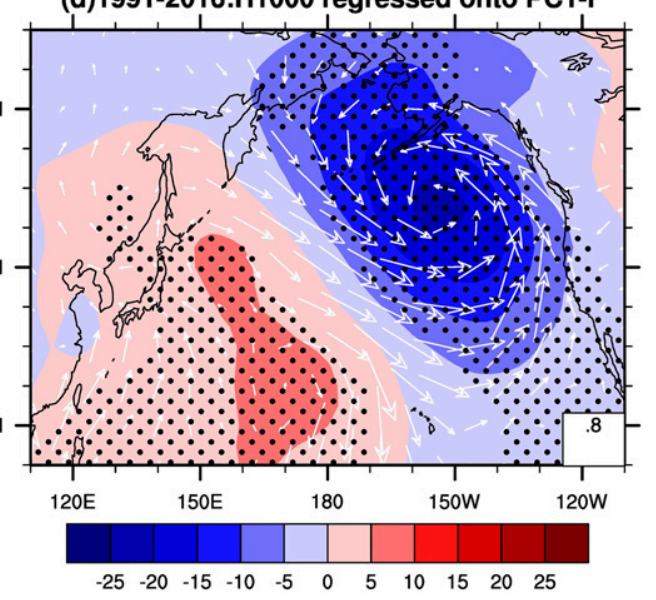

FIG. 6. Geopotential height ( $\mathrm{m}$; colors) and horizontal wind ( $\mathrm{m} \mathrm{s}^{-1}$; vectors) anomalies regressed onto the PC1-I index at (a) 500 and (b) $1000 \mathrm{hPa}$ during 1950-75. (c),(d) As in (a) and (b), but for 1991-2016. The dotted regions are statistically significant at the $95 \%$ confidence level according to Student's $t$ test.

Fig. 8c). This subtropical westerly anomaly is also evident in Fig. 9a $\left(20^{\circ}-40^{\circ} \mathrm{N}\right.$; red line), which displays the zonal mean zonal wind anomalies associated with ENSO. Furthermore, this westerly anomaly forces a positive vorticity anomaly by zonal wind shear $(-\partial u / \partial y)$ on the north side of the westerly anomaly $\left(35^{\circ}-50^{\circ} \mathrm{N}\right.$; red line in Fig. 9c). However, during the POST era, the tropical GH anomaly belt becomes narrower (Fig. 8b), inducing the southward shifting of the subtropical westerly anomaly and positive vorticity forcing of the zonal wind shear (blue lines; Figs. 9a,c). For the North Pacific, the processes are similar; the narrowing of the tropical $\mathrm{GH}$ anomaly favors the southward shift of the subtropical westerly anomaly over the North Pacific (blue line, Fig. 9b) and thereby the southward shift of the positive vorticity anomaly induced by zonal wind shear during the POST era (colors in Fig. 9f and blue line in Fig. 9d).

Furthermore, the positive vorticity anomaly (Figs. 9e,f) induced by anomalous zonal wind shear favors a cyclonic circulation anomaly (negative GH anomaly) over the North Pacific (Fig. 7). Thus, the southward shift of this positive vorticity forcing (Fig. 9d) favors the southward shift of the negative $\mathrm{GH}$ anomaly (cyclonic circulation anomaly) during the POST era (Fig. 7d) compared to that during the PRE era (Fig. 7a). Furthermore, the southward shift of the negative GH anomaly (cyclonic circulation anomaly) over the North Pacific (Fig. 7d) forces the PC1-I-like SSTAs to shift southward during the POST era (green contour; Fig. 7f) compared to that during PRE era (red contour; Fig. 7f). Now, a question arises as to why the tropical GH anomaly associated with ENSO becomes narrower during the POST era. Figures 8e and 8f show the ENSO-related SSTAs in the tropics. Note that the meridional width of ENSO refers to the meridional width of the tropical Pacific SSTAs associated with ENSO (180 -90 $\mathrm{W}$; Zhang et al. 2009; Zhang and Jin 2012; Zhang et al. 2013), and the 0.4-K contour (green line; Figs. $8 \mathrm{e}, \mathrm{f}$ ) is shown to easily compare changes in the meridional width of ENSO. Note that the meridional width of ENSO is narrower during the POST era (Fig. 8f) than during the PRE era (Fig. 8e), consistent with Zhang et al. (2009), who found that the meridional width of ENSO becomes narrower in recent decades. This narrowing of the ENSO meridional width corresponds to the narrowing of the tropical $\mathrm{GH}$ anomaly associated with 

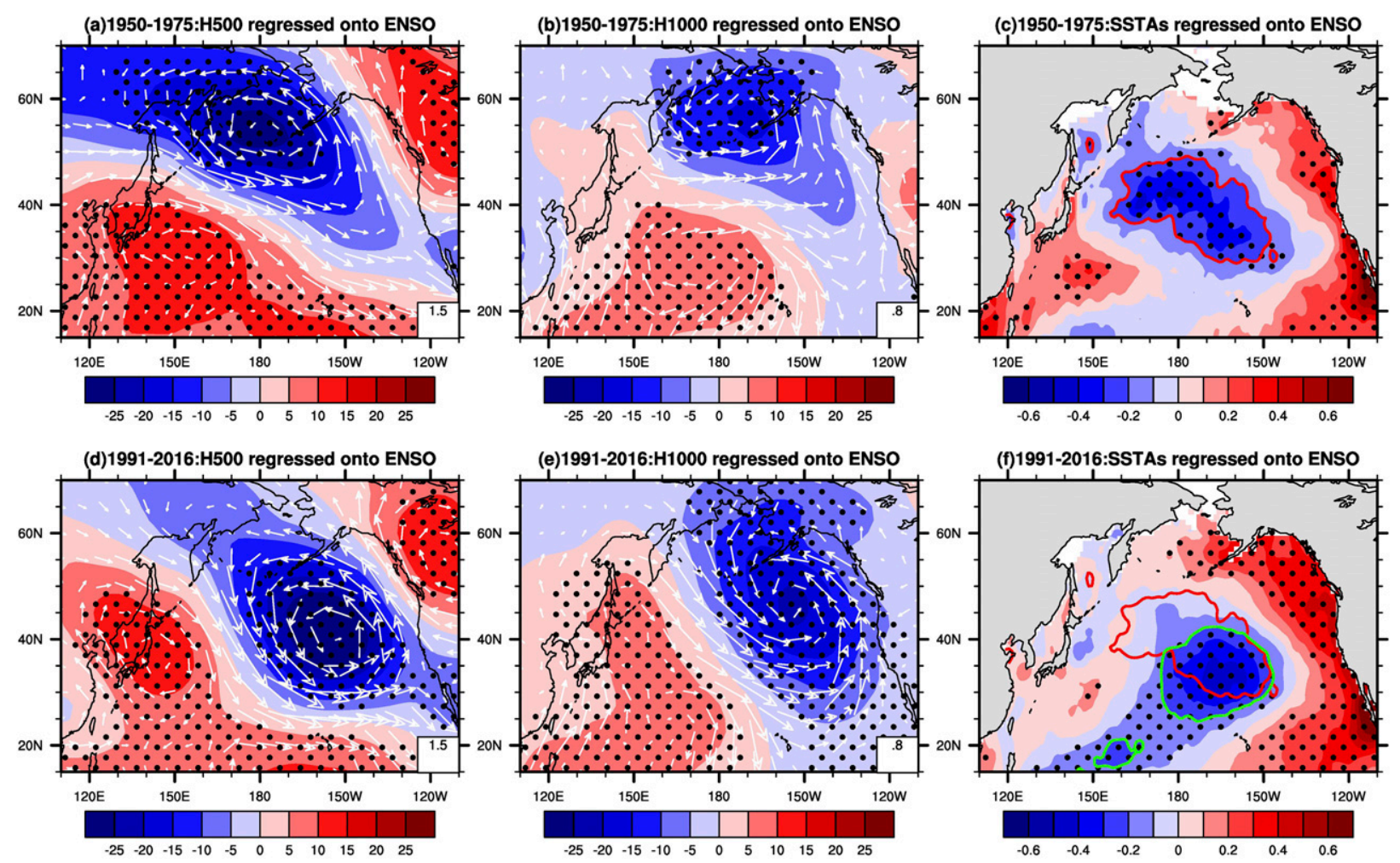

FIG. 7. Geopotential height ( $\mathrm{m}$; colors) and horizontal wind $\left(\mathrm{m} \mathrm{s}^{-1}\right.$; vectors) anomalies regressed onto the Niño-3.4 index at (a) 500 and (b) 1000 hPa during 1950-75. (d),(e) As in (a) and (b), but for 1991-2016. (c),(f) SSTAs regressed onto the Niño-3.4 index during 1950-75 and 1991-2016 from HadISST, respectively. The red and green contours denote the $-0.2-\mathrm{K}$ contour of the SSTA fields in (c) and (f), respectively. To facilitate direct comparison, the red contour in (c) is superimposed on (f). The dotted regions are statistically significant at the $95 \%$ confidence level according to Student's $t$ test.

ENSO during the POST era (Fig. 8b). Thus, the narrow meridional width of ENSO may contribute to the narrow tropical GH anomaly associated with ENSO and thereby contribute to the southward shift of the PC1-I anomaly during the POST era.

To verify the effects of the ENSO meridional width on the meridional positions of the PC1-I anomaly, we use the results of 26 CMIP5 models with outstanding abilities to simulate the observed close relationship between the ENSO variability and the North Pacific SST variability. The details of the 26 models are shown in section 2c. The meridional width of ENSO is calculated based on SSTAs regressed onto the Niño-3.4 index in each model. The meridional profiles of ENSO in these models and in the HadISST dataset are shown in Figs. 10a and 10b. The $e$-folding width of ENSO is defined as the width by which the meridional profile of ENSO-related SSTAs reaches $1 / e$, similar to the method used by Zhang and Jin (2012). According to the ENSO meridional width, the top $25 \%$ widest model outputs (GFDL-ESM2G, IPSLCM5A-LR, MIROC-ESM, MIROC-ESM-CHEM, MPI-ESMLR, and MPI-ESM-MR, referred to hereafter as "wide-ENSO models") and the $25 \%$ narrowest model outputs (CanESM2, FGOALS-g2, GFDL CM3, INM-CM4, MRI-CGCM3, and MRI-ESM1, referred to hereafter as "narrow-ENSO models") are used to perform a comparative analysis.

Figure 10a displays the meridional profile of ENSO in the reanalysis data. ENSO is narrower during the POST era (blue line) than during the PRE era (red line). Figure 10c shows the ENSO-related SSTAs in the North Pacific $\left(150^{\circ} \mathrm{E}-150^{\circ} \mathrm{W}\right)$ obtained from the reanalysis data. The negative SSTAs in Fig. 10c represent the meridional position of the PC1-I anomaly induced by ENSO (Figs. 7c,f). Clearly, the position of the PC1-I anomaly induced by the narrower ENSO (blue line, Fig. 10c) shifts southward compared to that induced by the wider ENSO (red line, Fig. 10c) in the reanalysis data. Figure 10b shows the meridional profiles of ENSO obtained from the wide-ENSO models (red line) and narrow-ENSO models (blue line). The simulated SSTAs associated with ENSO averaged in the North Pacific are shown in Fig. 10d, indicating that the PC1-I anomaly induced by the narrower ENSO (blue line) shifts southward compared to that induced by the wider ENSO (red line). Figures $10 \mathrm{e}$ and $10 \mathrm{f}$ further indicate that the PC1-I anomaly induced by the narrower ENSO (green contour) shifts southward compared to that induced by the wider ENSO (yellow contour), consistent with Fig. 10d. Therefore, both the reanalysis data (Figs. 10a,c) and modeling results (Figs. 10b,d-f) support that the narrowing of the meridional width of ENSO contributes to the southward shift of the PC1-I anomaly.

Figures 11a and 11d show tropical precipitation anomalies regressed onto ENSO in the wide-ENSO models and narrowENSO models, respectively. The tropical precipitation anomalies induced by the narrow (wide) ENSO are narrow (wide) 
(a) $\mathrm{H} 500$ (1950-1975)

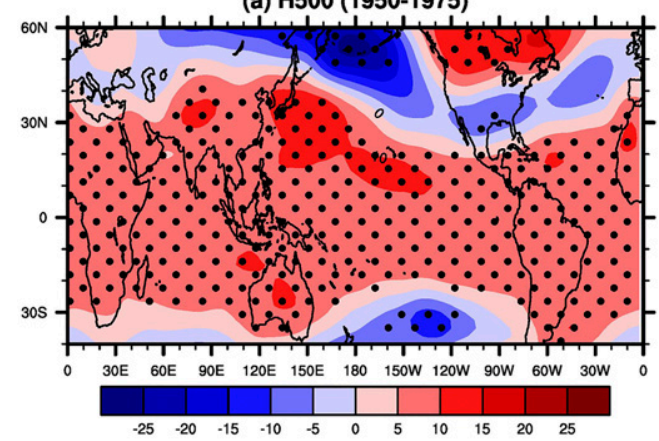

(c) U500 (1950-1975)

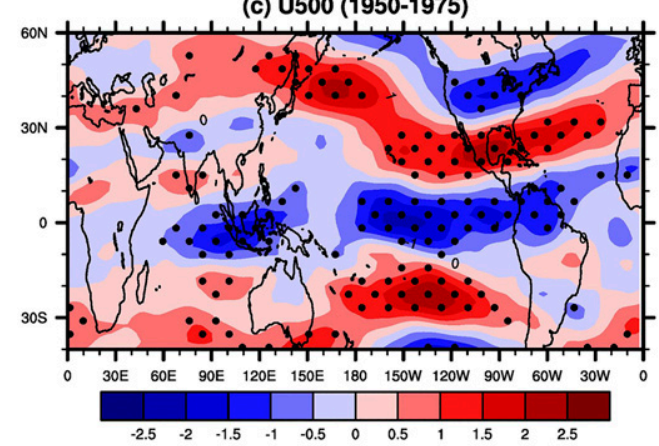

(e) SSTAs (1950-1975)

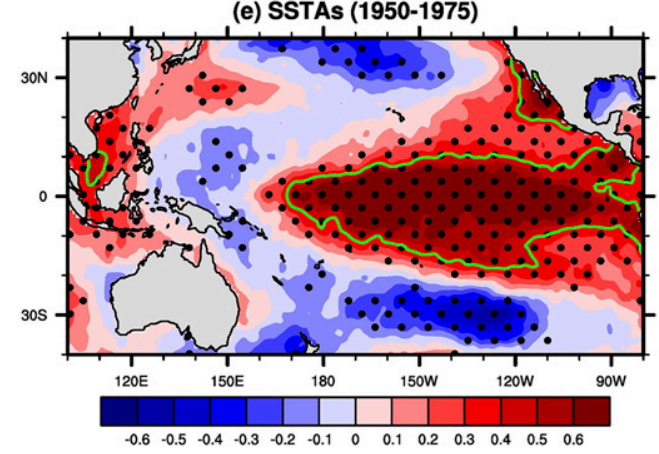

(b) $\mathrm{H} 500$ (1991-2016)

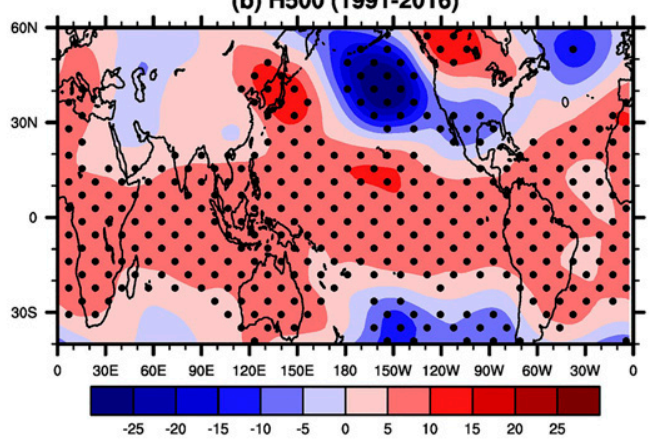

(d) U500 (1991-2016)

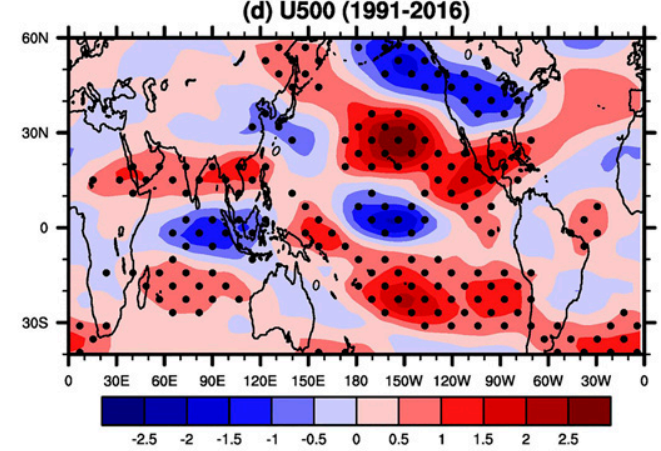

(f) SSTAs (1991-2016)

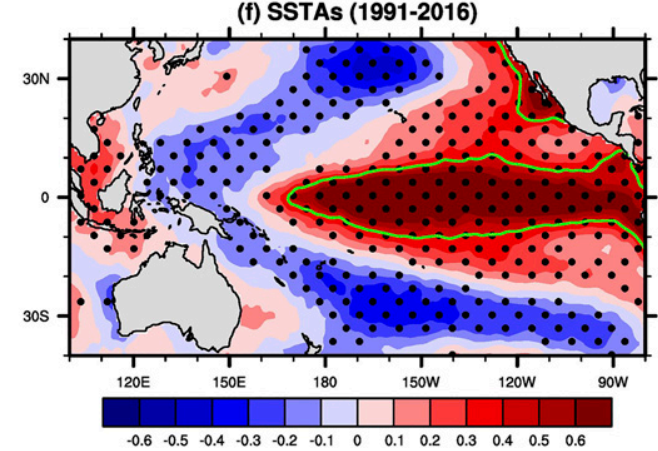

FIG. 8. Geopotential height anomalies (m) at $500 \mathrm{hPa}$ regressed onto the Niño-3.4 index during (a) 1950-75 and (b) 1991-2016. (c),(d) As in (a) and (b), but for zonal wind anomalies $\left(\mathrm{m} \mathrm{s}^{-1}\right)$. (e),(f) As in (a) and (b), but for the tropical Pacific SSTAs (K) based on HadISST. The green contours (0.4-K contours) are shown in (e) and (f) to compare changes in the meridional width of ENSO. The dotted regions are statistically significant at the $95 \%$ confidence level according to Student's $t$ test.

(Figs. 11a,d and 12a), further forcing positive tropical GH anomalies with narrow (wide) meridional widths (Figs. 11b,e) via latent heat release. Specifically, the significant positive $\mathrm{GH}$ anomalies induced by the narrow ENSO over the tropics do not exceed $20^{\circ} \mathrm{N}$ (blue contour, Fig. 11e). However, the tropical GH anomalies induced by the wide ENSO are wider and extend farther north to $30^{\circ} \mathrm{N}$ (black contour, Fig. 11b), especially over the middle and western Pacific $\left(0^{\circ}-30^{\circ} \mathrm{N}, 110^{\circ}-180^{\circ} \mathrm{E}\right)$. Furthermore, the narrow, positive $\mathrm{GH}$ anomaly induced by the narrow ENSO over the tropics favors a southward shift of the subtropical westerly anomaly (color, Fig. 11f) compared to that induced by the wide ENSO (color, Fig. 11c) through geostrophic wind relations. This southward-shifting subtropical westerly anomaly induces the positive vorticity forcing to shift southward over the North Pacific (contour, Fig. 11f), which then contributes to the southward shift of the negative $\mathrm{GH}$ anomaly (cyclonic circulation anomaly) over the North Pacific (Fig. 11e). Therefore, the modeling results support that the decrease in the ENSO meridional width (i.e., the narrowing of ENSO) contributes to the southward shift of the PC1-I anomaly (Figs. 10d,f) by inducing the southward shift of the negative $\mathrm{GH}$ anomaly (cyclonic circulation anomaly) over the North Pacific (Figs. 11e and 12b).

Notably, although the physical origins of the first leading mode of the North Pacific SST are not very clear at present, previous studies proposed several physical mechanisms (e.g., Latif and Barnett 1994, 1996; Newman et al. 2003; Sasaki et al. 2013; Miyasaka et al. 2014; Fang and Yang 2016), such as the forcing from ENSO, midlatitude air-sea interactions, ocean gyre 
(a) Zonal mean $\mathrm{U}$ anomaly

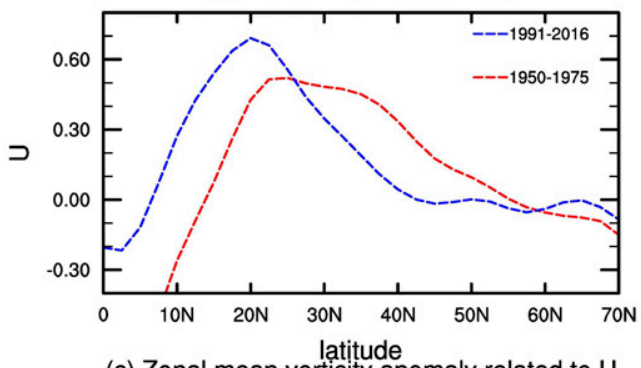

(c) Zonal mean vorticity anomaly related to $U$

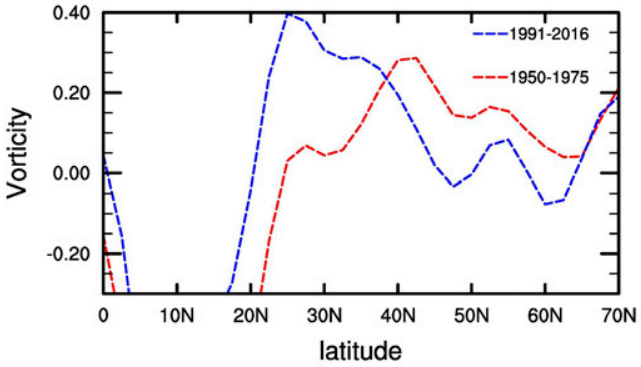

(e) Vorticity anomaly related to U (1950-1975)

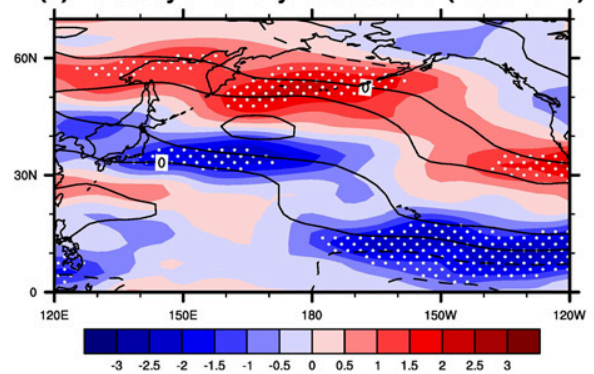

(b) U anomaly over North Pacific

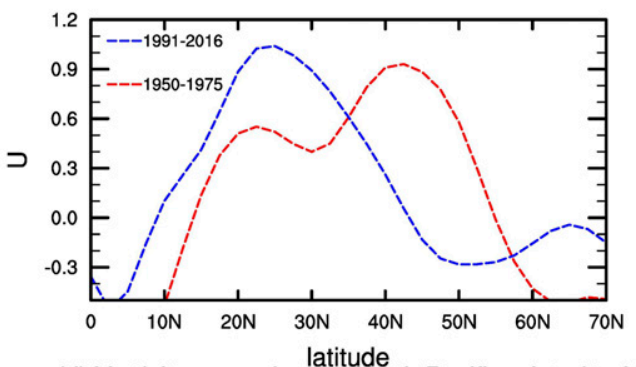

(d) Vorticity anomaly over North Pacific related to U

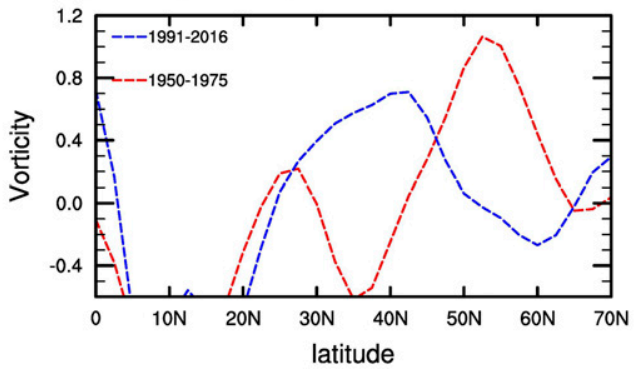

(f) Vorticity anomaly related to U (1991-2016)

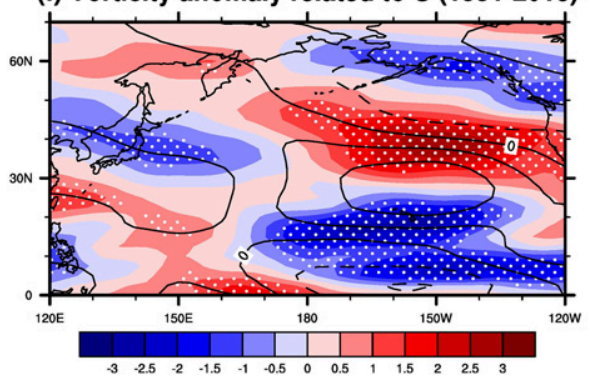

FIG. 9. (a) Zonal mean $\left(180^{\circ}-180^{\circ}\right)$ zonal wind anomaly $\left(\mathrm{m} \mathrm{s}^{-1}\right)$ at $500 \mathrm{hPa}$ regressed onto the Niño-3.4 index during 1950-75 (red line) and 1991-2016 (blue line). (b) As in (a), but for the zonal wind anomaly over the North Pacific $\left(120^{\circ} \mathrm{E}-120^{\circ} \mathrm{W}\right)$. (c) Zonal mean vorticity anomaly $\left(1 \times 10^{-6} \mathrm{~s}^{-1}\right)$ contributed by the zonal wind shear (i.e., $-\partial u / \partial y$ ) regressed onto the Niño-3.4 index during 1950-75 (red line) and 1991-2016 (blue line). (d) As in (c), but for the North Pacific. (e),(f) Vorticity anomalies $\left(1 \times 10^{-6} \mathrm{~s}^{-1}\right.$; color $)$ contributed by the zonal wind shear $(-\partial u / \partial y)$ and zonal wind anomalies ( $\mathrm{m} \mathrm{s}^{-1}$; contour) regressed onto the Niño-3.4 index during 1950-75 and 1991-2016, respectively. The solid and dashed contours denote positive and negative zonal wind anomalies, respectively. The dotted regions are statistically significant at the $95 \%$ confidence level according to Student's $t$ test.

dynamics involving Rossby waves, etc. Moreover, many studies reported that ENSO can force the North Pacific SSTAs similar to the PC1-I (Fig. 7) via the so-called atmospheric bridge (e.g., Newman et al. 2003, 2016; Schneider and Cornuelle 2005). This implies that ENSO may be one important factor that contributes to the North Pacific SST variability. Note that this study is not intended to illustrate that ENSO is the only factor that induces the southward shift the PC1-I-related SSTAs. Our results suggest that ENSO may be one important factor that contributes to the southward shift the PC1-I-related SSTAs. Figure 13 indicates that the PC1-I-related SSTAs significantly shift southward at a rate of $1.04^{\circ}$ latitude decade ${ }^{-1}$ since the 1960 s (blue line). However, when the ENSO signal in PC1-I is removed, the PC1I-related SSTAs still shift southward at a rate of $0.05^{\circ}$ decade $^{-1}$ (red line). Thus, there should be other factors that contribute weakly to the southward shift of the PC1-I-related SSTAs, and corresponding mechanisms may be different from these proposed by this study. Considering the length of this paper, future work is needed to explore other factors that contribute to the meridional position changes of the PC1-I-related SSTAs and corresponding physical mechanisms.

\section{Conclusions and discussion}

Using reanalysis datasets, observations, and climate model output, this study investigated changes in the meridional position of SSTAs associated with the PC1-I, which denotes the interannual component of the principal component 1 (PC1) of the first leading mode of the North Pacific SST (Fig. 1b). It is found that since the 1960s, the PC1-I-related SSTAs (or PC1-I anomaly) significantly shift southward at a rate of $1.04^{\circ}$ decade $^{-1}$ $\left(\sim 116 \mathrm{~km} \mathrm{decade}^{-1}\right.$ ) (Fig. 5). The central latitudes of the PC1-Irelated SSTAs in the 1960s, 1970s, 1980s, 1990s, and 2000s are $39.2^{\circ}, 37.7^{\circ}, 37.4^{\circ}, 36.2^{\circ}$, and $34.8^{\circ} \mathrm{N}$, respectively, indicating that 
(a) ENSO-related tropical SSTAs in HadISST

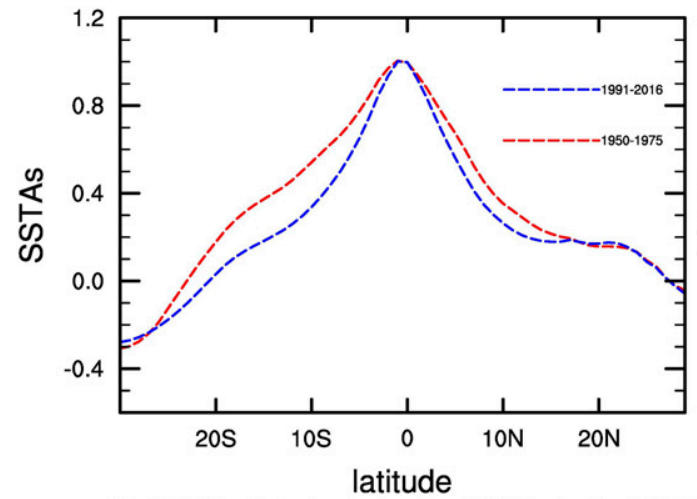

(c) ENSO-related extratropical SSTAs in HadISST

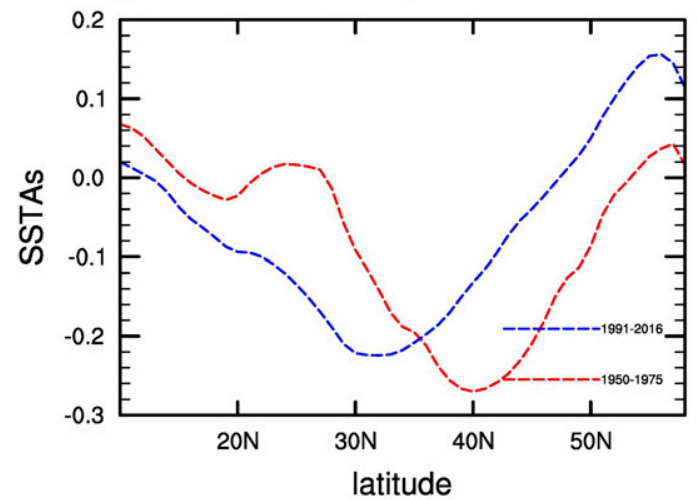

(e) SSTAs associated with wide ENSO

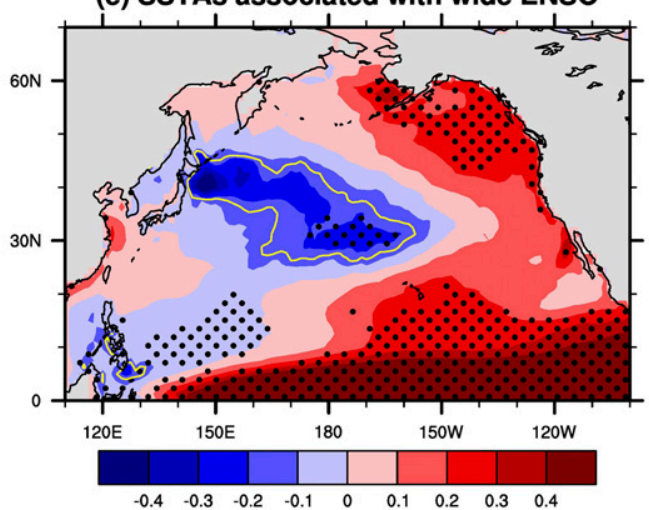

(b) ENSO-related tropical SSTAs in CMIP5

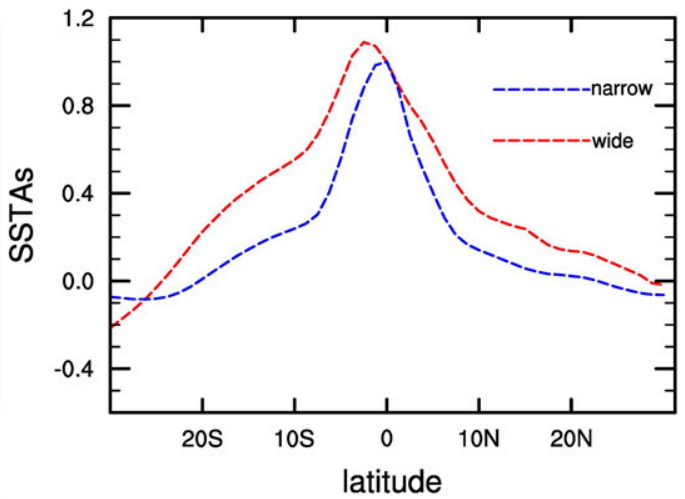

(d) ENSO-related extratropical SSTAs in CMIP5

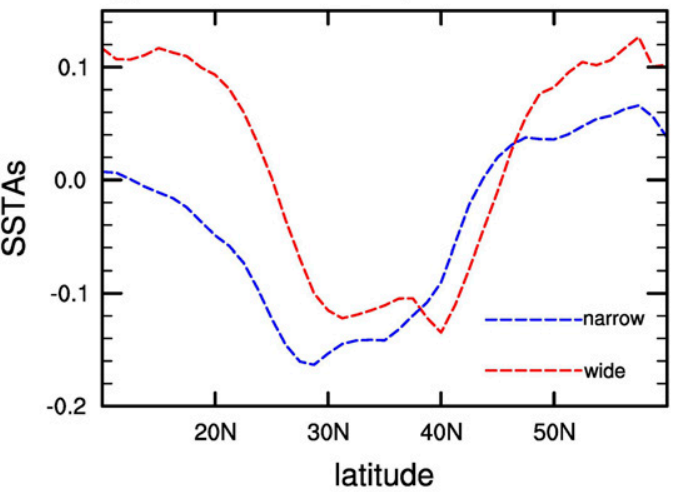

(f) SSTAs associated with narrow ENSO

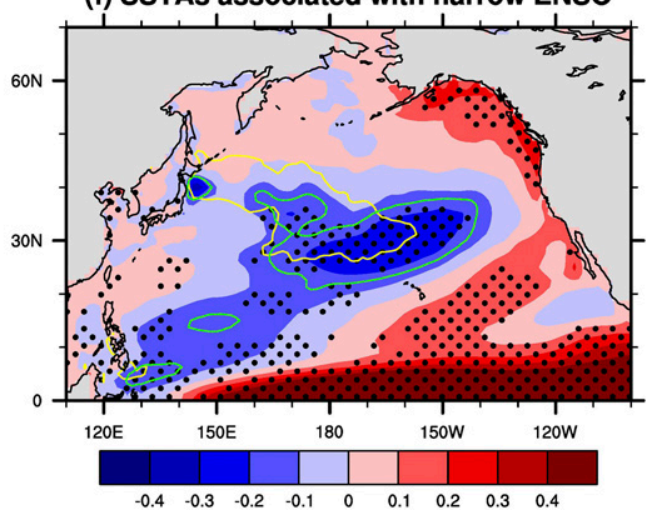

FIG. 10. (a) Tropical Pacific SSTAs (K, averaged over $\left.180^{\circ}-90^{\circ} \mathrm{W}\right)$ regressed onto the Niño-3.4 index in HadISST during 1950-75 (red line) and 1991-2016 (blue line). (b) Tropical Pacific SSTAs regressed onto the Niño-3.4 index in the wide-ENSO models (red line; i.e., GFDL-ESM2G, IPSL-CM5A-LR, MIROC-ESM, MIROC-ESM-CHEM, MPI-ESM-LR, and MPI-ESM-MR) and narrow-ENSO models (blue line; i.e., CanESM2, FGOALS-g2, GFDL CM3, INM-CM4, MRI-CGCM3, and MRI-ESM1). (c) As in (a), but for extratropical SSTAs in the North Pacific (averaged over $150^{\circ} \mathrm{E}-150^{\circ} \mathrm{W}$ ). (d) As in (b), but for extratropical SSTAs in the North Pacific (averaged over $140^{\circ} \mathrm{E}-$ $\left.140^{\circ} \mathrm{W}\right)$. (e),(f) SSTAs regressed onto the Niño-3.4 index in the wide-ENSO and narrow-ENSO models, respectively. The yellow and green contours denote the $-0.15-\mathrm{K}$ contour of the SSTAs in (e) and (f), respectively. The yellow contour in (e) is superimposed on (f) to facilitate direct comparison. The dotted regions are statistically significant at the $90 \%$ confidence level according to Student's $t$ test.

the PC1-I-related SSTAs have shifted southward by $4.4^{\circ}$ of latitude since the 1960s.

Based on a comparative analysis between the PRE era (195075) and POST era (1991-2016), we found that the southward shift of the PC1-I anomaly is related to changes in ENSO teleconnections: 1) During the PRE era, the ENSO-induced tropical positive GH anomaly is wide (Fig. 8a), which leads to a subtropical westerly anomaly over the North Pacific (Fig. 8c) 
(a) Precipitation associated with wide ENSO

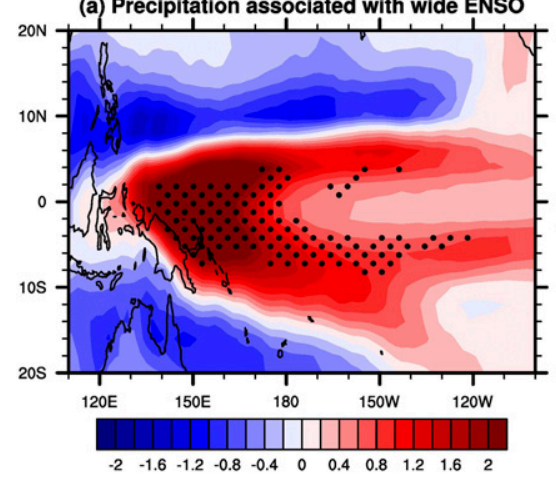

$\begin{array}{lllllllllllll}-2 & -1.6 & -1.2 & -0.8 & -0.4 & 0 & 0.4 & 0.8 & 1.2 & 1.6 & 2\end{array}$

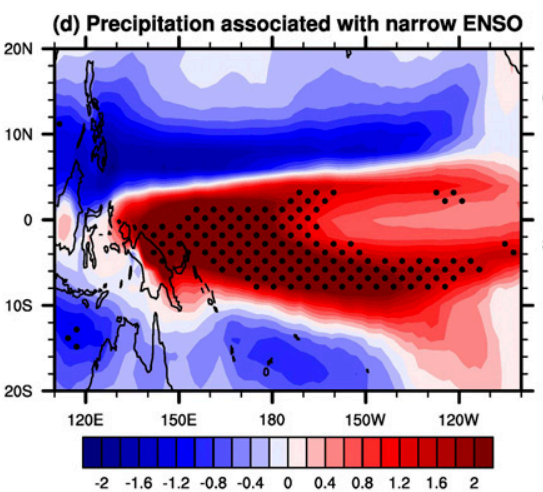

(b) $\mathrm{H} 500$ associated with wide ENSO

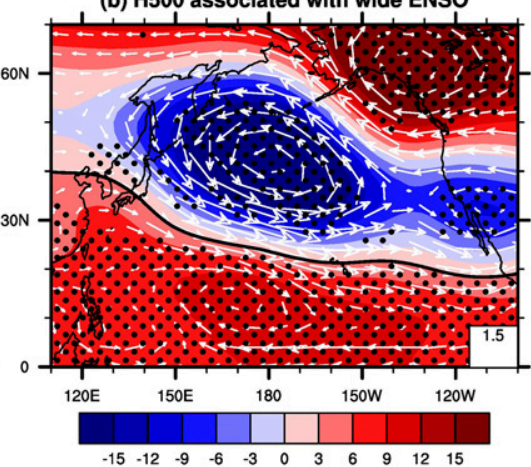

(e) H500 associated with narrow ENSO

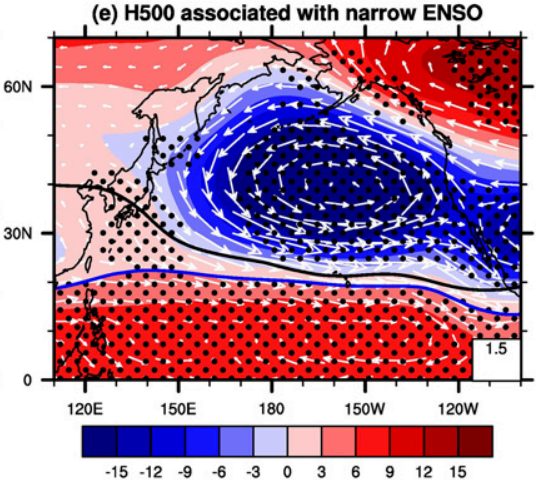

(c) U \& Vorticity associated with wide ENSO

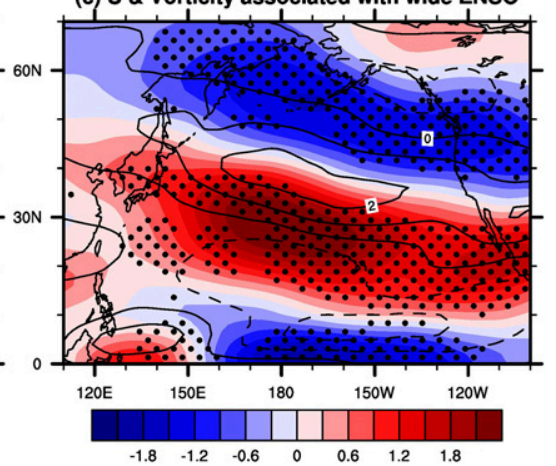

(f) U \& Vorticity associated with narrow ENSO

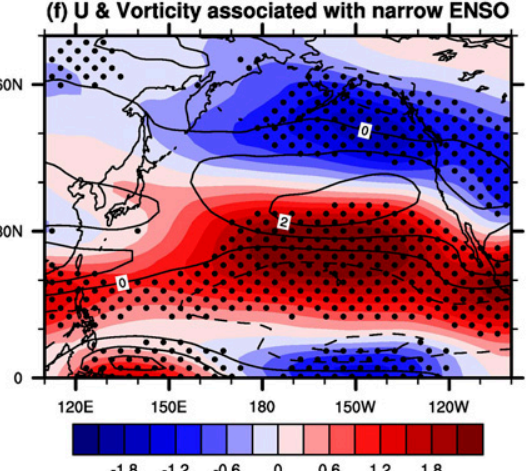

FIG. 11. (a) Tropical precipitation anomalies $\left(\mathrm{mm} \mathrm{day}^{-1}\right)$, (b) geopotential height ( $\mathrm{m}$; colors) and horizontal wind ( $\mathrm{m} \mathrm{s}^{-1}$; arrows) anomalies at $500 \mathrm{hPa},(\mathrm{c})$ zonal wind anomalies $\left(\mathrm{m} \mathrm{s}^{-1}\right.$; color) at $500 \mathrm{hPa}$ regressed onto the Niño-3.4 index in the wide-ENSO models. The contour in $(\mathrm{c})$ denotes the vorticity anomaly $\left(1 \times 10^{-6} \mathrm{~s}^{-1}\right)$ induced by zonal wind shear $(-\partial u / \partial y)$ regressed onto Niño-3.4 in the wideENSO models, and the solid and dashed contours denote positive and negative vorticity anomalies, respectively. (d)-(f) As in (a)-(c), but for the anomalies regressed onto the Niño-3.4 index in the narrow-ENSO models. The black and blue contours in (b) and (e) denote the 3-gpm contours of the geopotential height anomaly field in (b) and (e), respectively. The black contour in (b) is superimposed on (e) to facilitate the comparison of the position. The dotted regions are statistically significant at the $90 \%$ confidence level according to Student's $t$ test.

through geostrophic wind relations. This westerly anomaly further favors the cyclonic circulation anomaly (negative $\mathrm{GH}$ anomaly) over the North Pacific (Fig. 7a) due to the positive vorticity forcing of anomalous zonal wind shear (Fig. 9e and red line in Fig. 9d). However, during the POST era, the ENSO-induced tropical positive GH anomaly becomes narrower (Fig. 8b), inducing the subtropical westerly anomaly to shift southward (blue line, Fig. 9b) compared to its position (a) ENSO-related tropical precipitation

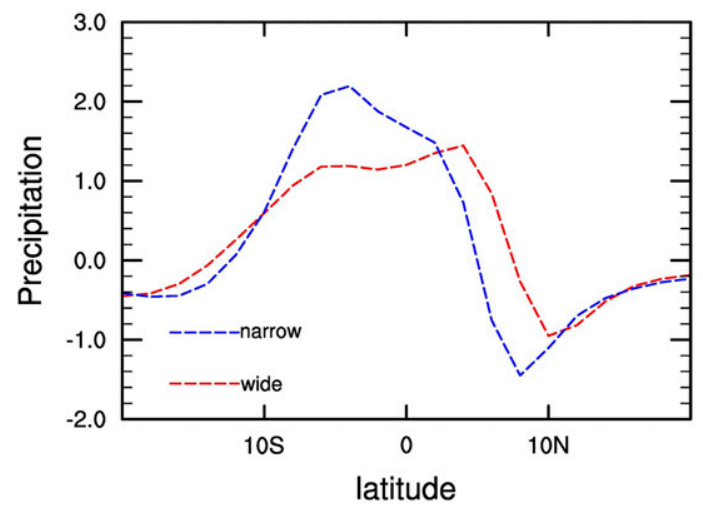

(b) ENSO-related geopotential height $(500 \mathrm{hPa})$

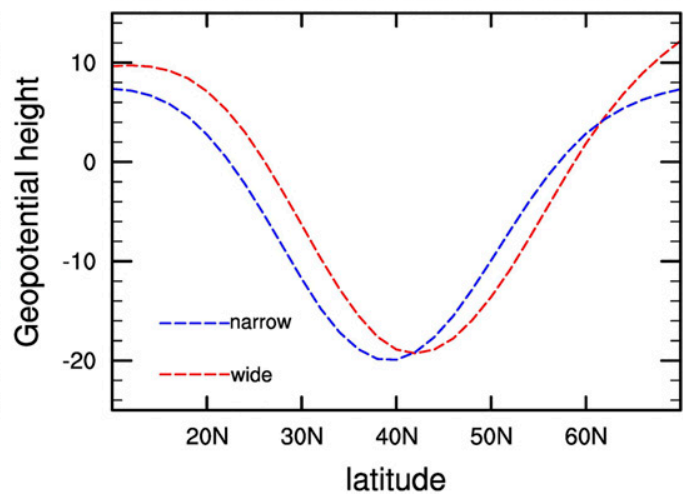

FIG. 12. (a) Tropical Pacific $\left(130^{\circ} \mathrm{E}-120^{\circ} \mathrm{W}\right)$ precipitation anomalies $\left(\mathrm{mm} \mathrm{day}^{-1}\right)$ regressed onto the Niño-3.4 index in the wide-ENSO (red line) and narrow-ENSO (blue line) models. (b) As in (a), but for geopotential height $(\mathrm{GH})$ anomalies $(\mathrm{m})$ over the North Pacific at $500 \mathrm{hPa}$. Specifically, based on the position of the negative GH anomaly center over the North Pacific associated with ENSO in Fig. 11, the GH anomalies are averaged over $140^{\circ} \mathrm{E}-150^{\circ} \mathrm{W}$ and over $150^{\circ} \mathrm{E}-120^{\circ} \mathrm{W}$ for the wide-ENSO and narrow-ENSO models, respectively. 


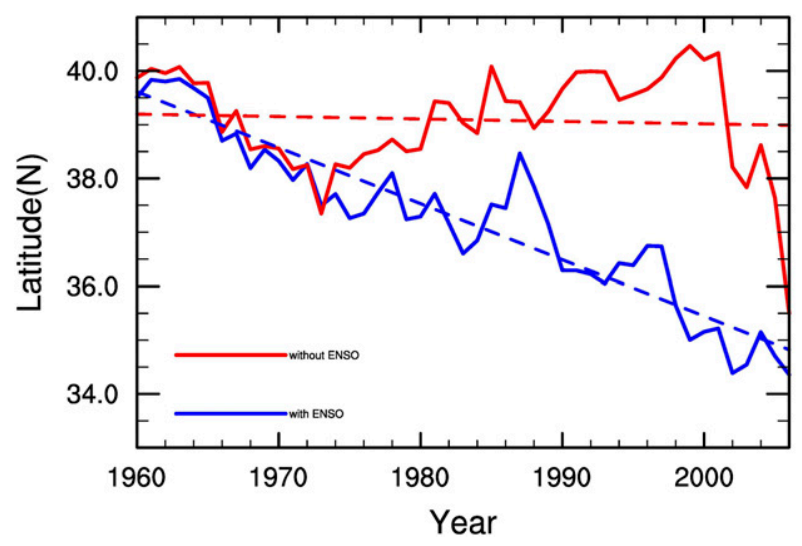

FIG. 13. Blue solid line: Time series of the central latitude of the PC1-I-related SSTAs based on approach 1, the border of $-0.2-\mathrm{K}$ and HadISST. Red solid line: Same as the blue solid line but the ENSO signal in PC1-I is removed by a linear regression method. In other words, the blue line contains ENSO signal while the red line does not. The dashed lines are the corresponding linear fit lines. The linear trend of the blue solid line is $-1.04^{\circ}$ decade $^{-1}$ and is statistically significant at the $99 \%$ confidence level. The linear trend of the red solid line is $-0.05^{\circ}$ decade $^{-1}$ and is not statistically significant.

during the PRE era (red line, Fig. 9b) through geostrophic wind relations. Therefore, the positive vorticity forcing of the anomalous zonal wind shear also shifts southward during the POST era $\left(30^{\circ}-45^{\circ} \mathrm{N}\right.$, blue line in Fig. $\left.9 \mathrm{~d}\right)$ compared to that during the PRE era $\left(50^{\circ}-60^{\circ} \mathrm{N}\right.$, red line in Fig. 9d), favoring the southward shift of the cyclonic circulation anomaly (negative GH anomaly) over the North Pacific during the POST era (Fig. 7d). Note that this cyclonic circulation anomaly over the North Pacific forces the PC1-I-like SSTAs (Figs. 7c,f) through surface heat fluxes, wind-driven mixing, and Ekman transport in the upper ocean (e.g., Alexander et al. 2002; Newman et al. 2003, 2016; Schneider and Cornuelle 2005; Alexander and Scott 2008; Fang and Yang 2016), and thus the southward shift of this cyclonic circulation anomaly favors the southward shift of the PC1-I-like SSTAs during the POST era (green contour; Fig. 7f). 2) Further analysis indicates that the narrow tropical GH anomalies associated with ENSO during the POST era are related to the narrow meridional width of ENSO (Figs. 8e,f). Coupled numerical simulations from CMIP5 support the premise that the tropical positive $\mathrm{GH}$ anomaly induced by the narrow ENSO is narrower (Fig. 11e) than that induced by the wide ENSO (Fig. 11b), which further leads to the southward shift of the subtropical westerly anomaly (color, Fig. 11f) compared to that associated with the wide ENSO (color, Fig. 11c). Furthermore, the southward shift of this westerly anomaly associated with the narrow ENSO favors the southward shift of the cyclonic circulation anomaly (negative GH anomaly) over the North Pacific (Figs. 11e and 12b) via the positive vorticity forcing of zonal wind shear (contour, Fig. 11f), forcing the PC1-I-like SSTAs to shift southward compared to that induced by the wide ENSO (Figs. 10d-f).

The above results indicate that the decrease in the meridional width of ENSO contributes to the southward shift of the circulation anomaly over the North Pacific and thereby the southward shift of the PC1-I anomaly. However, the ENSO structure includes its meridional extent (i.e., the ENSO meridional width) (Zhang et al. 2009, 2013; Zhang and Jin 2012) and zonal extent (i.e., the eastern-Pacific and central-Pacific El Niño events) (e.g., Ashok et al. 2007; Kao and Yu 2009; Yeh et al. 2009; Dewitte et al. 2012; Graf and Zanchettin 2012; Zhao et al. 2016; Cai et al. 2018; Yeh et al. 2018; Freund et al. 2019; Carréric et al. 2020). The eastern-Pacific and central-Pacific El Niño events also have effects on the extratropical climate, including the climate over the North Pacific and North America (e.g., Larkin and Harrison 2005; Weng et al. 2007; Garfinkel et al. 2012; Alizadeh-Choobari 2017; Li and Tian 2017; Yeh et al. 2018; Soulard et al. 2019; Shiozaki et al. 2021). Thus, a question arises as to whether the southward shift of the ENSOrelated circulation anomaly and PC1-I anomaly in the North Pacific is attributable to different ENSO types. We analyzed the changes in circulation anomalies and SSTAs over the North Pacific associated with the eastern Pacific El Niño (based on the ENSO Modoki index; Ashok et al. 2007) and those associated with the central Pacific El Niño (based on the Niño-3 index). We found that the meridional widths of the EMI and Niño-3 both decrease during the POST era compared to that during the PRE era, and the North Pacific circulation anomalies associated with the EMI and Niño-3 both shift southward during the POST era compared to that during the PRE era (not shown). This implies that the narrowing of the ENSO meridional width contributes to the southward shift of the PC1-I anomaly.

At present, there are relatively few studies on the position changes of various SST modes in the North Pacific. This study indicates that the PC1-I-related SSTAs significantly shift southward at a rate of $1.04^{\circ}$ latitude decade ${ }^{-1}$ since the $1960 \mathrm{~s}$, and the decrease in the ENSO meridional width contributes to the southward shift of the PC1-I-related SSTAs (Fig. 13). However, there are still some relevant questions that need to be explored in the future studies. First, previous studies found that the phase changes of the North Pacific SST modes have effects on the marine ecosystem and climate system (e.g., Miller and Schneider 2000; Barlow et al. 2001; Wang et al. 2015). This study suggests that the meridional position of the PC1-I-related SSTAs also experiences changes in past decades. Therefore, a question arises as to whether the position change of the SSTAs associated with the PC1-I also has effects on the marine ecosystem and climate system, which needs to be investigated in future work. Second, due to the limited length of various reanalysis datasets and considering the length of this paper, this study only discussed the position changes of the SSTAs associated with the interannual component of the first leading mode of the North Pacific SST. However, do the positions of the SSTAs associated with the decadal component of the first leading mode of the North Pacific SST also change? If yes, what are the corresponding physical mechanisms? These questions deserve to be further explored.

Acknowledgments. This work is supported by the National Natural Science Foundation of China (42130601, 41630421, 42075062) and the Fundamental Research Funds for the Central Universities (lzujbky-2021-ey04). We thank the scientific teams 
at NCEP and NCAR for providing the reanalysis data. We acknowledge the ESGF for providing the CMIP5 data.

\section{REFERENCES}

Alexander, M. A., and C. Deser, 1995: A mechanism for the recurrence of wintertime midlatitude SST anomalies. J. Phys. Oceanogr., 25, 122-137, https://doi.org/10.1175/1520-0485(1995) 025<0122:AMFTRO $>2.0 . \mathrm{CO} ; 2$.

, and J. D. Scott, 2008: The role of Ekman ocean heat transport in the Northern Hemisphere response to ENSO. J. Climate, 21, 5688-5707, https://doi.org/10.1175/2008JCLI2382.1.

—_, C. Deser, and M. S. Timlin, 1999: The reemergence of SST anomalies in the North Pacific Ocean. J. Climate, 12, 2419-2433, https://doi.org/10.1175/1520-0442(1999)012<2419: TROSAI $>2.0 . \mathrm{CO} ; 2$.

—, M. S. Timlin, and J. D. Scott, 2001: Winter-to-winter recurrence of sea surface temperature, salinity, and mixed layer depth anomalies. Prog. Oceanogr., 49, 41-61, https://doi.org/ 10.1016/S0079-6611(01)00015-5.

—- I. Bladé, M. Newman, J. R. Lanzante, N.-C. Lau, and J. D. Scott, 2002: The atmospheric bridge: The influence of ENSO teleconnections on air-sea interaction over the global oceans. J. Climate, 15, 2205-2231, https://doi.org/10.1175/ 1520-0442(2002)015<2205:TABTIO > 2.0.CO;2.

Alizadeh-Choobari, O., 2017: Contrasting global teleconnection features of the eastern Pacific and central Pacific El Niño events. Dyn. Atmos. Oceans, 80, 139-154, https://doi.org/ 10.1016/j.dynatmoce.2017.10.004.

Ashok, K., S. K. Behera, S. A. Rao, H. Weng, and T. Yamagata, 2007: El Niño Modoki and its possible teleconnection. J. Geophys. Res., 112, C11007, https://doi.org/10.1029/ 2006JC003798.

Barlow, M., S. Nigam, and E. H. Berbery, 2001: ENSO, Pacific decadal variability, and U.S. summertime precipitation, drought, and stream flow. J. Climate, 14, 2105-2128, https://doi.org/ 10.1175/1520-0442(2001)014<2105:EPDVAU>2.0.CO;2.

Biondi, F., A. Gershunov, and D. R. Cayan, 2001: North Pacific decadal climate variability since 1661 . J. Climate, 14, 5-10, https:// doi.org/10.1175/1520-0442(2001)014<0005:NPDCVS>2.0.CO;2.

Cai, W., and Coauthors, 2018: Increased variability of eastern Pacific El Niño under greenhouse warming. Nature, 564, 201206, https://doi.org/10.1038/s41586-018-0776-9.

Carréric, A., B. Dewitte, W. Cai, A. Capotondi, K. Takahashi, S.-W. Yeh, G. Wang, and V. Guémas, 2020: Change in strong eastern Pacific El Niño events dynamics in the warming climate. Climate Dyn., 54, 901-918, https://doi.org/10.1007/ s00382-019-05036-0.

Cayan, D. R., M. D. Dettinger, H. F. Diaz, and N. E. Graham, 1998: Decadal variability of precipitation over western North America. J. Climate, 11, 3148-3166, https://doi.org/10.1175/ 1520-0442(1998)011<3148:DVOPOW >2.0.CO;2.

Dettinger, M. D., D. R. Cayan, H. F. Diaz, and D. M. Meko, 1998: North-south precipitation patterns in western North America on interannual-to-decadal timescales. J. Climate, 11, 3095-3111, https://doi.org/10.1175/1520-0442(1998)011<3095: NSPPIW $>2.0 . \mathrm{CO} ; 2$

Dewitte, B., J. Choi, S.-I. An, and S. Thual, 2012: Vertical structure variability and equatorial waves during central Pacific and eastern Pacific El Niño in a coupled general circulation model. Climate Dyn., 38, 2275-2289, https://doi.org/10.1007/s00382-011-1215-x.

Fang, J., and X. Yang, 2016: Structure and dynamics of decadal anomalies in the wintertime midlatitude North Pacific ocean-atmosphere system. Climate Dyn., 47, 1989-2007, https://doi.org/10.1007/s00382015-2946-x.

Frankignoul, C., P. Müller, and E. Zorita, 1997: A simple model of the decadal response of the ocean to stochastic wind forcing. J. Phys. Oceanogr., 27, 1533-1546, https://doi.org/10.1175/ 1520-0485(1997)027<1533:ASMOTD>2.0.CO;2.

— N. Sennechael, Y. Kwon, and M. Alexander, 2011: Influence of the meridional shifts of the Kuroshio and the Oyashio Extensions on the atmospheric circulation. J. Climate, 24, 762777, https://doi.org/10.1175/2010JCLI3731.1.

Freund, M. B., B. J. Henley, D. J. Karoly, H. V. McGregor, N. J. Abram, and D. Dommenget, 2019: Higher frequency of central Pacific El Niño events in recent decades relative to past centuries. Nat. Geosci., 12, 450-455, https://doi.org/10.1038/ s41561-019-0353-3.

Garfinkel, C. I., M. M. Hurwitz, D. W. Waugh, and A. H. Butler, 2012: Are the teleconnections of Central Pacific and Eastern Pacific El Niño distinct in boreal wintertime? Climate Dyn., 41, 1835-1852, https://doi.org/10.1007/s00382-012-1570-2.

Graf, H. F., and D. Zanchettin, 2012: Central Pacific El Niño, the "subtropical bridge," and Eurasian climate. J. Geophys. Res., 117, D01102, https://doi.org/10.1029/2011JD016493.

Graham, N. E., 1994: Decadal-scale climate variability in the tropical and North Pacific during the 1970s and 1980s: Observations and model results. Climate Dyn., 10, 135-162, https://doi.org/10.1007/BF00210626.

He, S., H. Wang, and J. Liu, 2013: Changes in the relationship between ENSO and Asia-Pacific midlatitude winter atmospheric circulation. J. Climate, 26, 3377-3393, https://doi.org/ 10.1175/JCLI-D-12-00355.1.

$\mathrm{Hu}, \mathrm{D}$., and Z. Guan, 2018: Decadal relationship between the stratospheric Arctic vortex and Pacific decadal oscillation. J. Climate, 31, 3371-3386, https://doi.org/10.1175/JCLI-D17-0266.1.

Huang, B., and Coauthors, 2015: Extended Reconstructed Sea Surface Temperature version 4 (ERSST.v4). Part I: Upgrades and intercomparisons. J. Climate, 28, 911-930, https://doi.org/ 10.1175/JCLI-D-14-00006.1.

Hurwitz, M. M., P. A. Newman, and C. I. Garfinkel, 2012: On the influence of North Pacific sea surface temperature on the Arctic winter climate. J. Geophys. Res., 117, D19110, https:// doi.org/10.1029/2012JD017819.

Jadin, E. A., K. Wei, Y. A. Zyulyaeva, W. Chen, and L. Wang, 2010: Stratospheric wave activity and the Pacific decadal oscillation. J. Atmos. Sol.-Terr. Phys., 72, 1163-1170, https:// doi.org/10.1016/j.jastp.2010.07.009.

Kalnay, E., and Coauthors, 1996: The NCEP/NCAR 40-Year Reanalysis Project. Bull. Amer. Meteor. Soc., 77, 437-472, https:// doi.org/10.1175/1520-0477(1996)077<0437:TNYRP>2.0.CO;2.

Kao, H. Y., and J. Y. Yu, 2009: Contrasting eastern-Pacific and central-Pacific types of ENSO. J. Climate, 22, 615-632, https:// doi.org/10.1175/2008JCLI2309.1.

Krishnan, R., and M. Sugi, 2003: Pacific decadal oscillation and variability of the Indian summer monsoon rainfall. Climate Dyn., 21, 233-242, https://doi.org/10.1007/s00382-0030330-8.

Kwon, Y.-O., and C. Deser, 2007: North Pacific decadal variability in the Community Climate System Model version 2. J. Climate, 20, 2416-2433, https://doi.org/10.1175/JCLI4103.1.

Larkin, N. K., and D. E. Harrison, 2005: On the definition of El Niño and associated seasonal average U.S. weather anomalies. Geophys. Res. Lett., 32, L13705, https://doi.org/10.1029/ 2005 GL022738. 
Latif, M., and T. P. Barnett, 1994: Causes of decadal climate variability over the North Pacific and North America. Science, 266, 634-637, https://doi.org/10.1126/science.266.5185.634.

—_, and —_, 1996: Decadal climate variability over the North Pacific and North America: Dynamics and predictability. J. Climate, 9, 2407-2423, https://doi.org/10.1175/15200442(1996)009<2407:DCVOTN >2.0.CO;2.

Li, Y., and W. S. Tian, 2017: Different impact of central Pacific and eastern Pacific El Niño on the duration of sudden stratospheric warming. Adv. Atmos. Sci., 34, 771-782, https:// doi.org/10.1007/s00376-017-6286-0.

Liguori, G., and E. Di Lorenzo, 2018: Meridional modes and increasing Pacific decadal variability under anthropogenic forcing. Geophys. Res. Lett., 45, 983-991, https://doi.org/ 10.1002/2017GL076548.

Mantua, N. J., and S. R. Hare, 2002: The Pacific decadal oscillation. J. Oceanogr., 58, 35-44, https://doi.org/10.1023/A: 1015820616384.

— — — , Y. Zhang, J. M. Wallace, and R. C. Francis, 1997: A Pacific interdecadal climate oscillation with impacts on salmon production. Bull. Amer. Meteor. Soc., 78, 1069-1079, https://doi.org/ 10.1175/1520-0477(1997)078<1069:APICOW > 2.0.CO;2.

Miller, A. J., and N. Schneider, 2000: Interdecadal climate regime dynamics in the North Pacific Ocean: Theories, observations and ecosystem impacts. Prog. Oceanogr., 47, 355-379, https:// doi.org/10.1016/S0079-6611(00)00044-6.

— , D. R. Cayan, T. P. Barnett, N. E. Graham, and J. M. Oberhuber, 1994: Interdecadal variability of the Pacific Ocean: Model response to observed heat flux and wind stress anomalies. Climate Dyn., 9, 287-302, https://doi.org/10.1007/ BF00204744.

Minobe, S., 2000: Spatio-temporal structure of the pentadecadal variability over the North Pacific. Prog. Oceanogr., 47, 381408, https://doi.org/10.1016/S0079-6611(00)00042-2.

Miyasaka, T., H. Nakamura, B. Taguchi, and M. Nonaka, 2014: Multidecadal modulations of the low-frequency climate variability in the wintertime North Pacific since 1950. Geophys. Res. Lett., 41, 2948-2955, https://doi.org/10.1002/ 2014GL059696.

Namias, J., and R. M. Born, 1970: Temporal coherence in North Pacific sea-surface temperature patterns. J. Geophys. Res., $\mathbf{7 5}$, 5952-5955, https://doi.org/10.1029/JC075i030p05952.

$\longrightarrow$, and — 1974: Further studies of temporal coherence in North Pacific sea surface temperatures. J. Geophys. Res., 79, 797-798, https://doi.org/10.1029/JC079i006p00797.

Newman, M., G. P. Compo, and M. A. Alexander, 2003: ENSO-forced variability of the Pacific decadal oscillation. J. Climate, 16, 3853-3857, https://doi.org/10.1175/15200442(2003)016<3853:EVOTPD>2.0.CO;2.

— visited. J. Climate, 29, 4399-4427, https://doi.org/10.1175/ JCLI-D-15-0508.1.

Pak, G., Y.-H. Park, F. Vivier, Y.-O. Kwon, and K.-I. Chang, 2014: Regime-dependent nonstationary relationship between the East Asian winter monsoon and North Pacific Oscillation. J. Climate, 27, 8185-8204, https://doi.org/10.1175/JCLI-D-1300500.1 .

Qiu, B., and S. Chen, 2005: Variability of the Kuroshio Extension jet, recirculation gyre, and mesoscale eddies on decadal time scales. J. Phys. Oceanogr., 35, 2090-2103, https://doi.org/ 10.1175/JPO2807.1.

Rayner, N. A., and Coauthors, 2003: Global analyses of sea surface temperature, sea ice, and night marine air temperature since the late nineteenth century. J. Geophys. Res., 108, 4407, https://doi.org/10.1029/2002JD002670.

Sasaki, Y. N., and N. Schneider, 2011: Decadal shifts of the Kuroshio Extension jet: Application of thin-jet theory. J. Phys. Oceanogr., 41, 979-993, https://doi.org/10.1175/2010JPO4550.1.

— S. Minobe, and N. Schneider, 2013: Decadal response of the Kuroshio Extension jet to Rossby waves: Observation and thin-jet theory. J. Phys. Oceanogr., 43, 442-456, https:// doi.org/10.1175/JPO-D-12-096.1.

Schneider, N., and B. D. Cornuelle, 2005: The forcing of the Pacific decadal oscillation. J. Climate, 18, 4355-4373, https://doi.org/ 10.1175/JCLI3527.1.

Shiozaki, M., T. Enomoto, and K. Takaya, 2021: Disparate midlatitude responses to the eastern Pacific El Niño. J. Climate, 34, 773-786, https://doi.org/10.1175/JCLI-D-20-0246.1.

Soulard, N., H. Lin, and B. Yu, 2019: The changing relationship between ENSO and its extratropical response patterns. Sci. Rep., 9, 6507, https://doi.org/10.1038/s41598-01942922-3.

Taguchi, B., S.-P. Xie, N. Schneider, M. Nonaka, H. Sasaki, and Y. Sasai, 2007: Decadal variability of the Kuroshio Extension: Observations and an eddy-resolving model hindcast. J. Climate, 20, 2357-2377, https://doi.org/10.1175/JCLI4142.1.

, H. Nakamura, M. Nonaka, N. Komori, A. Kuwano-Yoshida, K. Takaya, and A. Goto, 2012: Seasonal evolutions of atmospheric response to decadal SST anomalies in the North Pacific subarctic frontal zone: Observations and a coupled model simulation. J. Climate, 25, 111-139, https://doi.org/ 10.1175/JCLI-D-11-00046.1.

Tao, L., X. Yang, J. Fang, and X. Sun, 2020: PDO-related wintertime atmospheric anomalies over the midlatitude North Pacific: Local versus remote SST forcing. J. Climate, 33, 69897010, https://doi.org/10.1175/JCLI-D-19-0143.1.

Trenberth, K. E., 1990: Recent observed interdecadal climate changes in the Northern Hemisphere. Bull. Amer. Meteor. Soc., 71, 988-993, https://doi.org/10.1175/1520-0477(1990) 071<0988:ROICCI $>2.0$. CO; 2 .

—_, and J. W. Hurrell, 1994: Decadal atmosphere-ocean variations in the Pacific. Climate Dyn., 9, 303-319, https://doi.org/ 10.1007/BF00204745.

Wang, H., and Coauthors, 2015: A review of seasonal climate prediction research in China. Adv. Atmos. Sci., 32, 149-168, https://doi.org/10.1007/s00376-014-0016-7.

Wang, L., W. Chen, and R. Huang, 2007: Changes in the variability of North Pacific Oscillation around 1975/1976 and its relationship with East Asian winter climate. J. Geophys. Res., 112, D11110, https://doi.org/10.1029/2006JD008054.

Weng, H., K. Ashok, S. K. Behera, S. A. Rao, and T. Yamagata, 2007: Impacts of recent El Niño Modoki dry/wet conditions in the Pacific Rim during boreal summer. Climate Dyn., 29, 113129, https://doi.org/10.1007/s00382-007-0234-0.

Woo, S. H., M. K. Sung, S. W. Son, and J. S. Kug, 2015: Connection between weak stratospheric vortex events and the Pacific decadal oscillation. Climate Dyn., 45, 3481-3492, https://doi.org/ 10.1007/s00382-015-2551-z.

Wu, S., Z. Liu, R. Zhang, and T. Delworth, 2011: On the observed relationship between the Pacific Decadal Oscillation and the Atlantic Multi-decadal Oscillation. J. Oceanogr., 67, 27-35, https://doi.org/10.1007/s10872-011-0003-X.

Yeh, S.-W., J.-S. Kug, B. Dewitte, M.-H. Kwon, B. P. Kirkman, and F.-F. Jin, 2009: El Niño in a changing climate. Nature, 461, 511-514, https://doi.org/10.1038/ nature 08316. 
and Coauthors, 2018: ENSO atmospheric teleconnections and their response to greenhouse gas forcing. Rev. Geophys., 56, 185-206, https://doi.org/10.1002/2017RG000568.

Zhang, P., Z. Wu, and H. Chen, 2017: Interdecadal variability of the ENSO-North Pacific atmospheric circulation in winter. Atmos.-Ocean, 55, 110-120, https://doi.org/10.1080/ 07055900.2017.1291411.

Zhang, W., and F. Jin, 2012: Improvements in the CMIP5 simulations of ENSO-SSTA meridional width. Geophys. Res. Lett., 39, L23704, https://doi.org/10.1029/2012GL053588.
- J. Li, and F. Jin, 2009: Spatial and temporal features of ENSO meridional scales. Geophys. Res. Lett., 36, L15605, https:// doi.org/10.1029/2009GL038672.

_ - F. Jin, J. Zhao, and J. Li, 2013: On the bias in simulated ENSO SSTA meridional widths of CMIP3 models. J. Climate, 26, 3173-3186, https://doi.org/10.1175/JCLI-D-12-00347.1.

Zhao, M., H. H. Hendon, O. Alves, G. Liu, and G. Wang, 2016: Weakened eastern Pacific El Niño predictability in the early twenty-first century. J. Climate, 29, 6805-6822, https://doi.org/ 10.1175/JCLI-D-15-0876.1. 